\title{
DEEP-SEA MOORINGS
}

\section{Design and Use with Unmanned Instrument Stations}

\author{
BY \\ JOHN D. ISAACS, JAMES L. FAUGHN, GEORGE B. SCHICK, \\ and MARSTON C. SARGENT
}

BULLETIN OF THE SCRIPPS INSTITUTION OF OCEANOGRAPHY OF THE UNIVERSITY OF CALIFORNIA

LA JOLLA, CALIFORNIA

Volume 8, No. 3, pp. 271-312, 14 figures in text

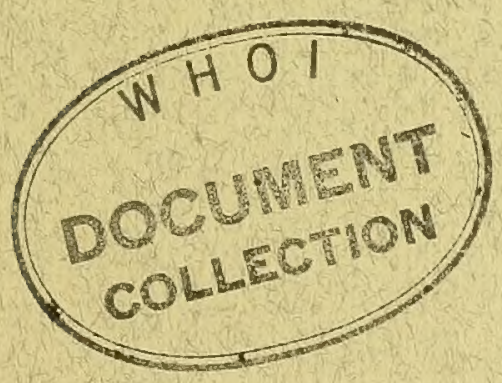

UNIVERSITY OF CALIFORNIA PRESS

BERKELEY AND LOS ANGELES

1963

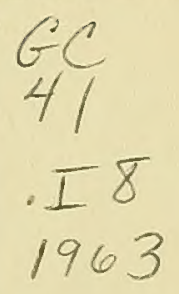




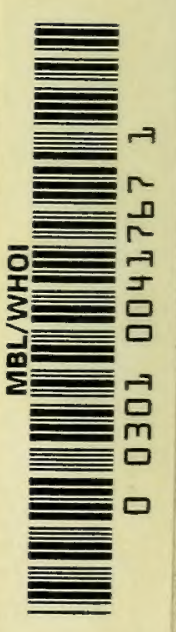




\title{
DEEP-SEA MOORINGS
}

\author{
Design and Use with \\ Unmanned Instrument Stations
}

\author{
BY \\ JOHN D. ISAACS, JAMES L. FAUGHN, GEORGE B. SCHICK, \\ and MARSTON C. SARGENT
}

BERKELEY AND LOS ANGELES 
Bulletin of the Scripps Institution of Oceanography of the University of California

LA JOLla, CALIFornia

Editors: D. L. Fox, G. O. S. Arrhenius, F. B. Phleger

Volume 8 , No. 3, pp. 271-312, 14 figures in text

Submitted by editors August 14, 1962

Issued March 14, 1963

Price, $\$ 2.00$

\author{
University of California Press \\ Berkeley and Los Angeles \\ California \\ Cambridge University Press \\ LONDON, ENGLAND
}

[CONTRIBUTIONS FROM THE SCRIPPS INSTITUTION OF OCEANOGRAPHY, NEW SERIES] 


\section{CONTENTS}

Abstract . . . . . . . . . . . . . . . . . . 271

Introduction . . . . . . . . . . . . . . . . . . . 271

Historical Background . . . . . . . . . . . . . . . . . 272

The Environment . . . . . . . . . . . . . . . . . . 273

Types of Moorings . . . . . . . . . . . . . . . . . . . 279

Taut-Wire Mooring Components . . . . . . . . . . . 280

Surface floats . . . . . . . . . . . . . . . . . 280

Spar buoys . . . . . . . . . . . . . . . . . 282

Pennants and instrument lines . . . . . . . . . . . . 282

The submerged float . . . . . . . . . . . . . . . . . . 283

Mooring cables . . . . . . . . . . . . . . . . . 284

Anchors . . . . . . . . . . . . . . . . . . 288

Fittings . . . . . . . . . . . . . . . . . . . 289

Bottom-detecting devices . . . . . . . . . . . . . . . 289

System Design . . . . . . . . . . . . . . . . . . . . . . 292

Acknowledgments . . . . . . . . . . . . . . . . . . 296

Appendix . . . . . . . . . . . . . . . . . . . . 297

Shipboard installations . . . . . . . . . . . . . . . . . . 297

Accessory handling equipment . . . . . . . . . . . . . 297

Spooling winch . . . . . . . . . . . . . . . . . . 297

Work davit . . . . . . . . . . . . . . . . . . . . . 297

Work platform . . . . . . . . . . . . . . . . . . . . 298

Skiff-retrieving ramp . . . . . . . . . . . . . . . . . 298

Navigational and accessory equipment . . . . . . . . . . 298

Mooring techniques . . . . . . . . . . . . . . . . . 298

Preparation for laying the mooring . . . . . . . . . . . 298

Mooring procedure . . . . . . . . . . . . . . . . . . 299

Servicing instrument stations . . . . . . . . . . . . . . . 301

Anchoring problems . . . . . . . . . . . . . . . . . . . 301

Retrievability of submerged float . . . . . . . . . . . . . 304

Corrections to echo-sounder readings for sound velocity . . . . . . . 304

Taut-nylon mooring . . . . . . . . . . . . . . . . . . 305

Basic computations for drag forces on the mooring . . . . . . . 306

Steps in the graphic solution of a deep-mooring configuration . . . . 308

Calculation of restoring forces on a surface float . . . . . . . . . . 309

Literature Cited . . . . . . . . . . . . . . . . 312

TABLES

1. Comparison of cables . . . . . . . . . . . . . . . . . 287

2. Velocity conversion factors . . . . . . . . . . . . . 292

3. Holding power of bottom . . . . . . . . . . . . . . . 302

4. Comparison of anchors . . . . . . . . . . . . . . 303

5. Drag coefficients . . . . . . . . . . . . . . 308

6. Sample calculation of forces . . . . . . . . . . . . . . 309 
Figures

1. Typical taut-wire mooring . . . . . . . . . . . . . . . . 274

2. Assumed current profile . . . . . . . . . . . . . . . . . 275

3. Effects of wave motion on mooring with buoyant pennant . . . . . 276

4. Deep-moored instrument skiff . . . . . . . . . . . . . . . 281

5. Shock-cord mooring pennant . . . . . . . . . . . . . . . 283

6. Self-reeling submerged float . . . . . . . . . . . . . . . 285

7. Ultimate tensile-strength requirement . . . . . . . . . . . 286

8. Forees on anchor on sloping bottom . . . . . . . . . . . . . 289

$9 a$. Wire terminal clamp . . . . . . . . . . . . . . . . . . 290

9b. Typical mooring-wire termination . . . . . . . . . . . . . 291

10. Excursion and dip of submerged float . . . . . . . . . . . . 294

11. Correction (in meters) to be added to recorded depth . . . . . . . 305

12. Taut-nylon deep-water mooring system _ . . . . . . . . . . 307

13. Graphic solution of deep-mooring configuration . . . . . . . . . 310

14. Restoring forces on a pennant . . . . . . . . . . . 311 


\title{
DEEP-SEA MOORINGS \\ Design and Use with Unmanned Instrument Stations
}

BY

\author{
JOHN D. ISAACS, JAMES L. FAUGHN, GEORGE B. SCHICK,
} AND MARSTON C. SARGENT

\begin{abstract}
This report describes methods that have been devised for mooring surface-instrument floats at fixed positions in the deep sea. The fundamental prineiples, the environmental factors, the design of equipment, and the over-all systems, techniques, and procedures at sea are discussed. Although most of the experience described has been with taut-wire moorings, the principles and the methods are of general application. Sources of information on environmental conditions in the ocean are listed, and examples of calculations are given.
\end{abstract}

\section{INTRODUCTION}

THE PRINCIPLES and the techniques discussed in this report relate to mooring light devices in the deep ocean at depths from 100 to 3,000 fathoms.

This report is a record of experience for the information of those who plan to design and install such deep-sea moorings. It is based on approximately eight years of work by members of the staff of the Scripps Institution of Oceanography who have, at times, maintained simultaneously as many as thirty moored stations distributed over thousands of square miles.

The large expanse of oceans is deep, unmarked, and constantly in motion. The oceans are a dynamic environment, differing from one moment to another. Because of this mobility we must attain a knowledge of the fluctuations before we can establish the significance of single sets of observations. It is as essential, for instance, for the oceanographer to understand movements of the water if he is to comprehend the events that take place in the sea, as it is for the meteorologist on land to understand the fluctuations of the systems of winds.

Almost all oceanographic investigations in the deep oceans today are still carried out aboard surface or subsurface vessels, and all these vessels are more or less affected by the dynamic nature of the oceanic environment. Through long experience and necessity, investigative and sampling techniques have been designed to take advantage of and work with the natural forces, the large areas, the great pressures, the distribution of features, and the lack of synopticity in the measurements.

The techniques may be broadly grouped under two operational types that ordinarily require inereasing control or knowledge of position of the measurement:

1) Under-way surveys, where ordinary navigation suffices and time series are not usually wanted, include plankton net and mid-water trawl hauls for biological sampling; bottom-dredge hauls for the sampling of benthic organisms; rock-dredge and mud-sampler hauls for geological and radiological sampling; bathymetric surveys; current surveys using the GEK (Geomagnetic-electro-kinetograph) technique; surface temperature surveys using thermitow, thermograph, or bathythermograph; and magnetic, gravity, and radiological surveys. 
2) Hove-to or maneuvering surveys, where the geographical control requires a virtual fixed point in space, include serial observations to determine the character of local time or space fluctuations in the distribution of properties; coring, deep drilling, mud sampling, vertical bathythermograph casts, vertical probing for radioactivity distribution, light penetration, and accurate determination of currents, waves, plankton spottiness, and other variations with time.

The present diseussion will be limited to the second group, above. The primary intent of deep-sea mooring is to maintain a surface float in some geographical position with the simplest effective system. The relatively steady forces that tend to displace the system are primarily the horizontal drag forces imposed on the components by wind and current. These are applied principally near the surface. Intermittent impulsive or oscillating forces, both horizontal and vertical, are imposed by the waves, and these forces dictate many of the design characteristics of the system. The force available to the designer for resisting the displacement of the system is almost solely shear force on the bottom material (although other possibilities exist). The problem thus is to conduct the horizontal drag forces, generated near the surface, some miles vertically so that they are resisted by the bottom frictional forces, and to do this in a manner compatible with the other forces and design restraints.

\section{HISTORICAL BACKGROUND}

The history of deep moorings dates back at least as far as 1888-1889, when the U.S. Coast and Geodetic Survey Steamer Blake, under the command of J. E. Pillsbury, carried out studies of the Gulf Stream. During these investigations the Blake was anchored at several localities in depths to 4,000 meters. Subsequently, other vessels were anchored in great depths in the North Atlantic and elsewhere. Some vessels, including the Meteor, have been anchored in depths greater than 4,500 meters for periods up to two weeks, and the Meteor was anchored in 5,500 meters for two days. According to Sysoyev (1957), the Vitiaz was anchored for many hours at a depth of 9,600 meters. Sysoyev's historical review and critical study of the entire deep-anchoring problem (brought to our attention by J. D. Frautschy, Assistant Director of the Seripps Institution) contains much useful information.

Because of the weight of the wire involved when anchoring in the deep oceans, the wire ropes usually are tapered, multistrand steel ropes of a nonkinking variety. The wire ropes used on the Blake and the Meteor had a diameter at the free end of about $3 / 8$ inch, which increased to about $5 / 8$ inch at the winch end. Various types of anchors have been used, either singly or in pairs, which weighed between 400 and 500 pounds. Generally, the anchors have been either of a standard variety with somewhat enlarged flukes, or of the mushroom pattern. The $E$. W. Scripps was anchored successfully in depths of about 1,600 meters with a Danforth anchor weighing only 40 pounds.

The actual technique and equipment used for deep anchoring has varied from ship to ship and with the sea and wind conditions at the time. Usually, however, the wire rope is led through an accumulator to ease the impulsive loading, over a dynamometer, through a braking device, and then over a large sheave or roller 
mounted on the bow. The depth of water must be known, and some means of metering the wire is necessary to permit proper laying of the anchor without fouling.

When anchoring in the open sea, scopes ("scope" is the ratio of the length of mooring line to depth) of 1.1 to 1.6 have been used, and, when anchoring in the strong currents of the Gulf Stream, scopes of 2.0 to 3.0 have been used.

The "taut mooring" was first deseribed by Bascom (1953). Figure 1 shows a more recent form of this mooring, designed by John D. Isaacs, Robert P. Huffer, and Lewis W. Kidd, which is adapted for use in any depth of water (1957).

The original installations were designed to fulfill as nearly as possible a requirement for a rigidly fixed reference point to which water motions (waves and currents) could be related. The submerged float served as the required point, and provision was made for attachment of the necessary sensing elements. The surface float then provided an accessible platform upon which recording units and power supplies could be located and serviced.

As shown in figure 1, a typical station consists of a submerged float (1), held with considerable tension some 150 feet below the surface by a low-drag mooring line (2) connected with a suitable anchor (3). From the submerged float a slack rope (4) leads to a skiff (5) which floats on the sea surface and holds the recording instruments. The key to the system is the use of the submerged float for buoyancy and the taut wire of high tensile strength (and low drag) for the main mooring line.

\section{THE ENVIRONMENT}

The principal phenomena in the open sea which determine the design of mooring systems are (1) currents, (2) waves, and (3) the rapidity of corrosion and decay. Although other factors often assume great importance at some times and places, these three must be contended with all the time and everywhere.

1) Currents.-If there are no currents, a subsurface buoy connected with an anchor by a taut mooring line will hold the line in a vertical position. If horizontal currents exert drag on the buoy and the line, the line will be bent into a curve which, to a first approximation, may be considered an are of a circle. Because of this change in figure, the buoy will be pulled to a greater depth by an amount called its "dip." It will also be displaced down current by an amount called its "excursion." In designing a taut-wire mooring system it is necessary to know or to assume the actual current profile in order to select component dimensions that will give acceptable values for the dip and the excursion.

The current profile from top to bottom is not a straight line; the current diminishes with increasing depth but not linearly. Strong horizontal currents are restricted to the upper layer of the ocean where, owing to vertical mixing by wind and waves, the temperature and other characteristics are uniform. In this layer currents of one or two knots are common, and in some areas, as in the Gulf Stream, currents of three or four knots occur frequently. In much of the tropies the mixed layer is 200 to 400 feet deep throughout the year. In mid-latitudes it has an annual cycle, being very shallow in summer and reaching 300 to 600 feet in winter. There is a tendency for the layer to be deeper in the western portion of the oceans at 


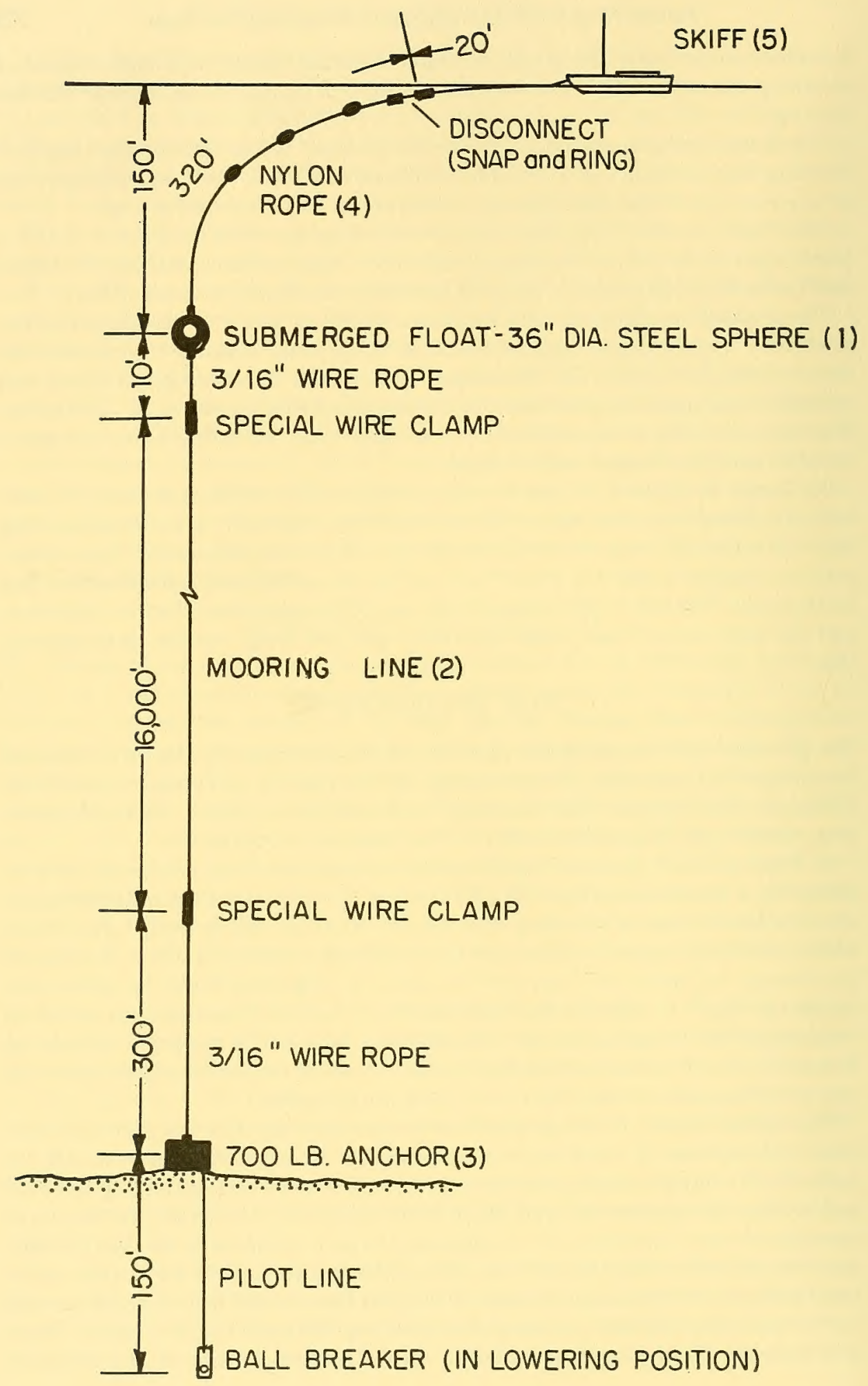

Fig. 1. Typical taut-wire mooring. 
mid-latitudes. Statistical information for many areas is given in the Atlas of Surface Currents (USN HO, 1944-1947). The depth of the mixed layer in the tropics and at mid-latitudes in summer may be obtained directly with a bathythermograph. Statistical information for middle and high latitudes in winter is scarce. In our experience moorings on isolated sea mounts (at about 700 fathoms) are much less satisfactory than moorings over the adjacent deep sea floor at 2,500 fathoms. In the Marshall Islands, at least, currents over deep sea mounts seem to be intensified.

The indicated surface current often reaches to the bottom of the mixed layer. Scattered observations indicate that currents below the mixed layer seldom exceed 0.5 knot. Observations at the bottom of the sea in deep water indicate that currents very seldom exceed 0.2 knot. At the Seripps Institution, when direct observations of current velocities below the surface are lacking, a rule of thumb is used in assuming the current profile below the mixed layer. This rule states that at the depth of temperature transition the current is assumed to be $0.5 \mathrm{knot}$, and, at the bottom, 0.2 knot. Direct observation or statistical information shows that below the mixed layer the temperature decreases rapidly with increasing depth in a relatively shallow zone, and then very slowly the remainder of the way to the bottom. Usually visual inspection of a vertical temperature profile is sufficient to identify the approximate depth at which the transition occurs. In the absence of a temperature profile, the depth of transition may be assumed to be 200 feet below the bottom of the mixed layer. The complete velocity profile assumed is shown in figure 2.

Obviously a measured current profile is preferable, but this ordinarily is not

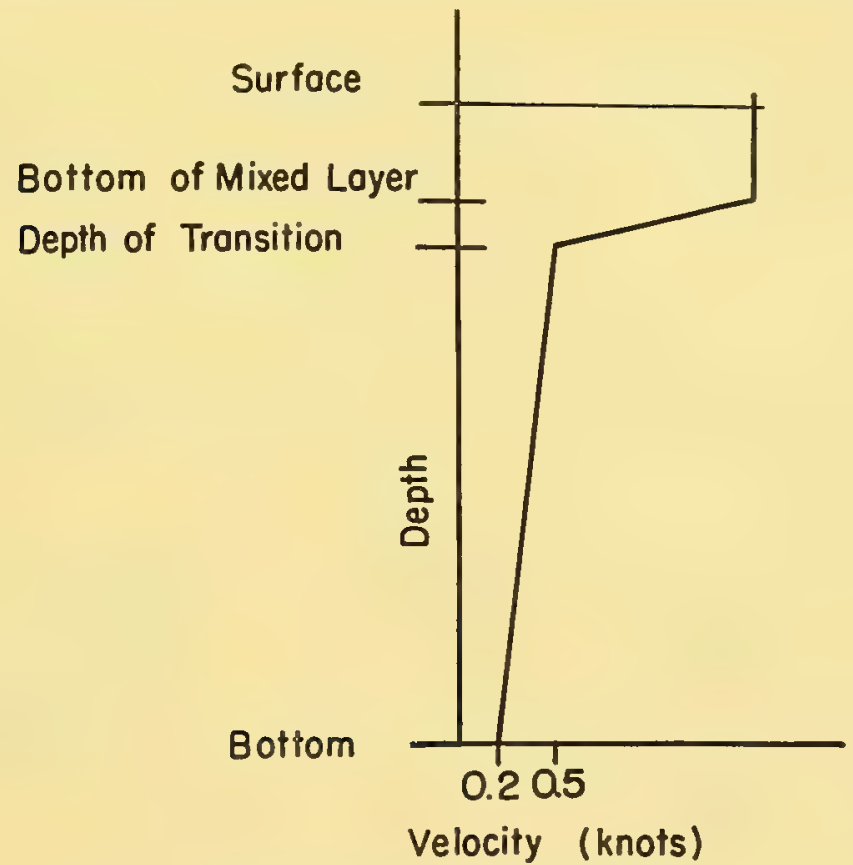

Fig. 2. Assumed current profile. 
available until the first moorings have been used. The assumption described is conservative to the degree that currents do not flow in the same direction. Indeed, submerged countercurrents cancel some of the stress in the mooring. The calculation is unconservative to the degree that transient currents may exceed the design current in the region. This is accommodated by factors of safety in the design, as discussed later.

It is clear that, with such a current profile, the horizontal drag on the system will be stronger when the mixed layer is deeper. In mid-latitudes this effect will produce an annual cycle in the dip and the excursion of a subsurface buoy. We have had opportunity to apply this rule of thumb in only a few areas in the Pacific. We advise caution in applying it too literally elsewhere, and suggest that all available information be studied as a possible basis for a better set of assumptions.

2) Waves.-The ceaseless motion owing to even small surface waves results in chafing, jerking, fouling of slack lines, and ultimate failure. An adequately designed mooring accommodates this attrition and is protected against premature damage or loss. Large waves and especially breaking storm waves (combers) in deep water, on the other hand, determine the strength requirements of moorings with surface floats because of the large impulsive loadings that the surface components undergo. Deep-moored systems without surface components, such as moored sonar targets used in station keeping or submerged recorders that emerge or transmit information on command, have much less stringent requirements in this respect.

The water in a nonbreaking deep-sea swell or wave follows an approximately circular orbit. Consider the orbiting of a body on the surface of the water as a result of wave action. Suppose we assume a wave 20 feet high $(H)$ of 8 -second period ( $\mathrm{T})$. A body would move in a circular orbit 20 feet in diameter with a velocity of $\mathrm{H} \pi / \mathrm{T}=(20 \times 3.1) / 8=7.8$ feet per second. The length of this wave in deep water would be approximately 325 feet, and the rate of travel of its crest (phase velocity) would be 24 knots (40 feet per second). Figure 3 illustrates the

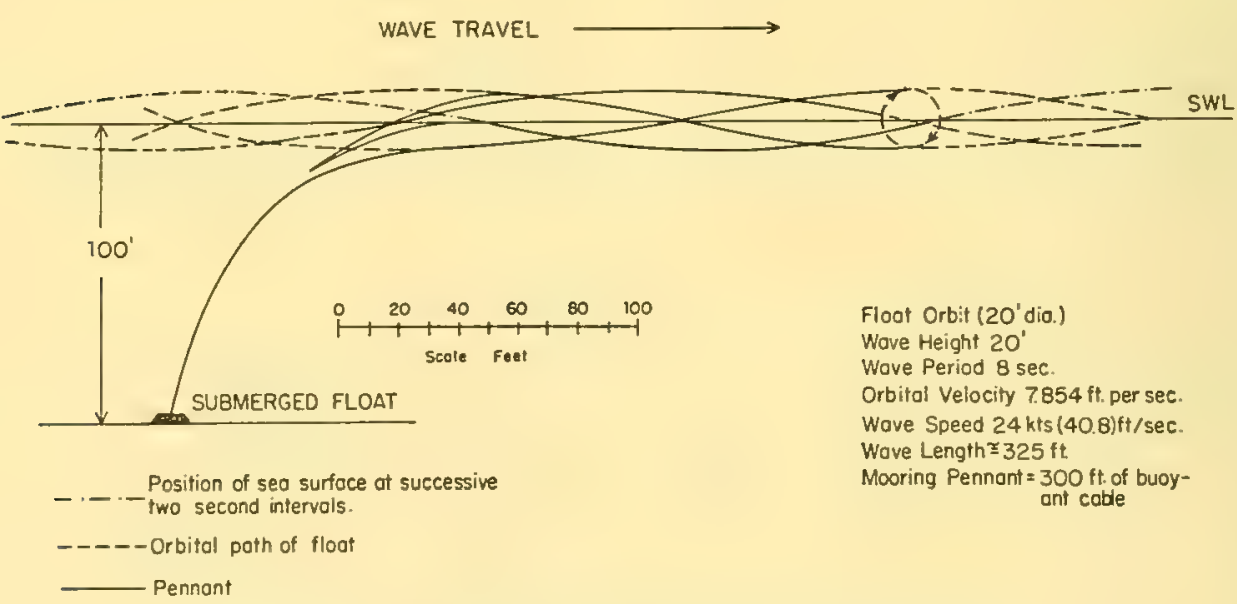

Fig. 3. Effects of wave motion on mooring with buoyant pennant. 
effect on a mooring with a buoyant pennant. A submerged float will move in a reduced orbit, which ean be estimated from tables such as those of Wiegel (1954).

It should be kept in mind that there may be large differences between the behavior in the real sea and the behavior in ideal waves. No matter how appealing the customary assumption of regular trochoidal waves from the standpoint of simplicity, such an assumption may exaggerate elementary motions (as rolling and pitching) on the one hand, and may fail to give satisfactory explanations of such matters as slamming and lurching on the other. It is necessary also to take into account the extreme conditions met during storms, when waves are steep and confused, and often break.

In a breaking deep-sea wave or comber, a moored surface float is struck by a cascade of water perhaps $1 / 3$ the height of the wave. This cascade moves essentially at the wave (phase) velocity for a distance of about $1 / 3$ of a wave length. The following wave may also break, subjecting the mooring to extreme stress and excursion.

The size of waves is controlled by the velocity, the fetch, and the duration of winds. The Marine Climatic Atlas of the World (U. S. Navy, 1955-1959) shows for each region of the ocean the percentage frequency of wind of each Beaufort force from 2 through 9 . Tables relating wave size to wind are given in Wind Waves at Sea, Breakers and Surf (USN HO, 1947, pp. 17-18).

If the greatest height $\left(\mathrm{H}_{\mathrm{c}}\right)$ of the waves producing deep-sea combers is estimated for a region, the wave length $\left(\mathrm{L}_{0}\right)$, the period $(\mathrm{T})$, and the velocity $\left(\mathrm{C}_{0}\right)$ may be approximated as follows:

$$
\begin{aligned}
& \mathrm{L}_{0}=7 \mathrm{H}_{\mathrm{c}} \text { feet (for the steepest storm waves) } \\
& \mathrm{T}=\left(\mathrm{L}_{0} / 5.12\right)^{1 / 2} \text {, or } \mathrm{T}=1.1\left(\mathrm{H}_{\mathrm{c}}\right)^{1 / 2} \text { seconds } \\
& \mathrm{C}_{0}=\mathrm{L}_{0} / \mathrm{T} \text {, or } \mathrm{C}_{0}=6.0\left(\mathrm{H}_{\mathrm{c}}\right)^{1 / 2} \text { feet per second }
\end{aligned}
$$

(See Sverdrup, Johnson, and Fleming, 1942, pp. 525-527.)

Thus, in an area known to experience wave heights of 25 feet in storms, it may be estimated that the mooring will be struck from time to time by a cascade of water traveling at about 30 feet per second, and that this cascade will persist for about 60 feet. In such a breaking sea, a second comber is very likely to follow the first. This wave is likely to peak up during its passage through the wake of the previous comber and to begin breaking approximately at the point where the previous comber ceased breaking. Thus it is essential that the surface float be subject to enough restoring force to be pulled through the first comber at a rate that permits it to escape the following comber.

In storms in the deep sea, the dominant waves and winds are most likely to be in the same direction. Consequently, the wind stress may be considered as imposing an initial load or restoring force on the surface float that is being carried out of position by a breaking wave. This is because the steep approaching comber shields the surface float from the wind, and hence some of the resisting force in the mooring (which a moment previously resisted the wind drag) begins to move the float toward the approaching comber, and the float, if boat-shaped, is oriented by this effect. This condition does not necessarily obtain near fast-moving storm centers, of course, but a mooring has survived the close passage of the eye of one of the fast-moving chubascos of Mexican waters, where wind velocities were estimated at about 100 knots. 
3) Corrosion and decay.- The conductivity of sea water makes it essential that no dissimilar metals be in direct electrical contact. The potential difference even between hot-dipped and electrolytically galvanized parts is sufficient to cause failure if they are submerged and in contact for several months.

The oxygen concentration in some places in the open ocean is as low as $0.15 \mathrm{ml} / 1$ at mid-depths. Many metals, including some stainless steels, are inadequately protected at such low tensions.

It is well known that bacteria, fungi, and boring animals in the sea are very destructive to most organic materials. Either resistant or toxic coatings must be used, or components must be built of materials not subject to attack.

4) Other factors.-Sharks are voracious creatures of the deep sea which will strike or bite at any object that attracts their attention. A small float on a line, a tag end of line, or tape on an instrument cable is frequently bitten off or damaged by sharks. It is essential that every component appear continuous with the system in order to minimize shark bites. That is, tags, pigtails, and small floats of colors different from that of the line should be avoided.

Seaweed rafts appear close in to coasts, often at oceanic fronts. A surface pennant will become fouled by such rafts, and if the raft is large enough it will carry the mooring away. Nipa and rattan rafts of immense dimensions are present in some parts of the South Pacific. Where this problem is likely to be severe, and the mooring must survive for long periods of time, the mooring may of necessity have to be designed with no surface float.

Where sea ice is present, it is not possible to employ moorings with surface floats. In sleet or black-ice storms at high altitudes, ice may build up on the float. If these factors are hazards, the float should be designed to survive capsizal.

Near rocky coasts, seals and sea lions sometimes are troublesome in that they leap aboard and bask on any surface float large enough. They may break antennae or even capsize the float. They may be discouraged by designing the float without flat horizontal surfaces or by using a rough granular coating.

On the bottom in the deep ocean, there are a number of sharp objects: debris that has been jettisoned, wrecks, rock outcroppings and nodules, as well as, of course, the anchor. In general, therefore, any part of the mooring cable which is allowed to touch and drag on the bottom must be chain or flexible wire rope of high quality, several times stronger than the main mooring cable.

Perhaps the most difficult problem stems from human intervention. If the surface floats on a mooring are conspicuous, visually or by radar, passing craft will pull off course to investigate. If there are any floating lines about the float they are very likely to be picked up on the hull or in the screws and cut adrift or keelhauled. In addition, fishermen will tie up to the moorings, attempt to hoist them, or cut them free. In many instances this recovery is intended to be helpful. Regardless of warnings or information painted on the float, some seamen cannot believe that a floating object in 2,000 or 3,000 fathoms is moored there, and will salvage it and return it to its owner.

The importance of these environmental factors may perhaps be indicated by the fact that, of fifteen moorings broken loose and recovered by Scripps Institution, only two or three seemed to have failed from mechanical stress, fatigue, or 
abrasion. All others showed evidence of having been fouled by ships, cut free by fishermen, or, in several instances, bitten off by sharks. A broken shark tooth was recovered embedded in the end of one parted pennant.

\section{TYPES OF MOORINGS}

Many types of moorings are possible, and the type used should depend upon the specific requirements for the work at hand. A mooring may be slack or taut and may have either surface or submerged floats or both, and the depth of the submerged float may be specified. The mooring cable itself, as well as the floats, may or may not be instrumented. The degree of horizontal and vertical stability of the entire system or of particular elements may be of concern. The required longevity of the installation may be hours or months. Servicing at intervals may or may not be required, and servicing may be accomplished in situ or by retrieving and replacing the instrumented station and part of the upper pennant.

In this discussion we will consider only single-wire moorings, but two, three, or more mooring wires are possible, and may be necessary if the requirements for rigidity or minimum excursion are of paramount importance.

As explained in Bascom's paper (1953) the taut mooring was originally considered because it provided a relatively fixed point of reference to which water motions could be related. It should be pointed out and perhaps emphasized, however, that often the requirements for rigidity and minimum excursion will be the most difficult to meet and, where they are severe, may well multiply the cost and the complexity of the mooring many times. For these reasons alone it is advisable that the requirements for rigidity be carefully scrutinized each time with a view to reducing them to the minimum consistent with the results desired. An extreme example may be cited, in which one design of a station envisions the use of twelve separate anchors and is estimated to cost 27 million dollars!

An additional and important point is worth considering. In many instances it may be better to design instruments to filter out or otherwise compensate for some motion in the moored system than to impose unduly severe and perhaps costly requirements on the mooring.

The mooring must be so designed as (1) to provide the elasticity required to permit harmless dissipation of impulsive forces resulting from motions of the float in waves, and (2) to provide sufficient strength to resist the drag on the floats and the mooring component due to currents and wind. The anchor must be heavy enough to withstand the vertical components of the maximum pull, and it must engage enough shearing resistance of the bottom deposits to withstand the horizontal component of the maximum cable pull.

The slack-wire mooring is essentially a mooring of large scope. Basically its restraint to excursion under increased forces depends upon increased tension in the mooring line. Hence the major portion of the buoyancy of such a system must be on the surface, where these increases in tension may be balanced by increased displacement of the surface float. Unless the design of a slack mooring is very carefully undertaken, the lower portions of the line may become fouled on the bottom and may part (or at least greatly reduce the scope). A very ingenious slack mooring, invented by A. Vine of Woods Hole Oceanographic Institution, has been in 
successful use for some time. The mooring utilizes a lower line that is buoyant (polypropylene), and an upper portion that is nonbuoyant (nylon). The entire mooring eable therefore assumes a shape like that shown in the accompanying illustration, thus avoiding many of the problems of slack mooring and permitting installation by streaming.

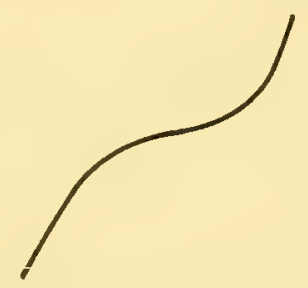

In the taut-wire configuration the adjustment to increased horizontal force is an inclination of an initially taut wire. There is little inerease in tension. Hence the major portion of the buoyancy in such a mooring may be submerged at some relatively constant depth where it is in the region of reduced currents and wave motion.

A common requirement of deep moorings is station keeping. For this requirement the taut-wire mooring is superior. The taut-wire mooring, however, requires much more rigorous design, handling, and installation procedures than the slack mooring; thus the latter may be preferred in some circumstances, particularly for installations from which only surface data are taken and for short-term installations.

\section{TAUT-WIRE MOORING COMPONENTS}

\section{Surface Floats}

Two general types of surface floats are feasible: (1) a surface-following float, such as a skiff or a nun buoy that tends to move with the waves, and (2) a stable float, such as a long-period spar or a "hydrometer-shaped" float whose vertical excursions in the presence of waves are small. Although each of these types has advantages, the present discussion will be limited to surface-following floats.

A primary requirement of the surface float is that it possess sufficient displacement to support its instrument and power load. The float should also be designed to support the weight of the mooring wire and the submerged float, so as to prevent the loss of the entire mooring if the submerged float leaks and fills. It should also carry a radar reflector and a flashing light to aid in homing on it and to warn ships against running it down. Figure 4 shows one type of float made of a glassreinforced plastic skiff.

The responding surface float should be designed so that a comber does not load its frontal area instantly. Thus a conical or boatlike bow is preferred. The float will then reach the velocity of the comber very rapidly, but not impulsively. As it is temporarily shielded from the wind, its early velocity in respect to the comber will be the speed imparted by a towing force equal to the wind drag. That is to say, as soon as the float is shielded from the wind, the tension in the cable due to the wind will be available to move the float through the water. This initial velocity 
may be estimated from towing and wind-drag curves for the hull, and approximately equals the way that the hull would make before the same wind. The orienting effect of this initial velocity at the approach of a comber is a very important factor and demands some wind drag in the design.

As the next comber will start to break at the point where the preceding one terminated, it is necessary that the surface float return part way toward its original position before the next comber breaks. Otherwise it will be carried farther from its original position, putting additional stress on the system and risking dangerous disorientation. The criterion of safe performance is that the stressed system shall move the surface float approximately $1 / 3$ of the distance it was dis-

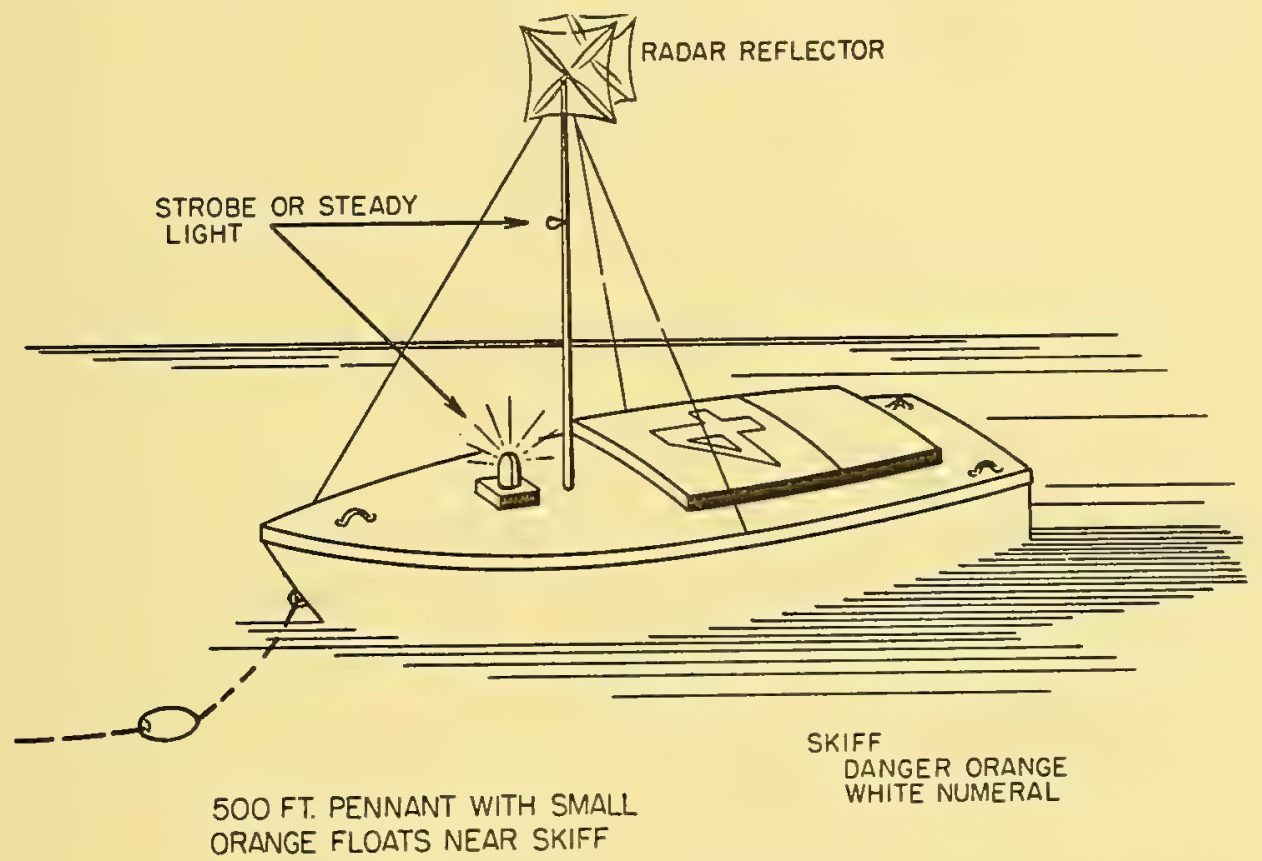

Fig. 4. Deep-moored instrument skiff.

placed by the first comber in the interval between the moment that the first comber breaks and the moment that the succeeding comber breaks. For safety, then, the surface float must move about $1 / 9$ of a wave length in $4 / 3$ of the wave period, or at an average velocity of $1 / 12$ of the phase velocity. The elasticity of the pennant provides the larger part of the available restoring force. Thus a 10 per cent elongation of a half-inch nylon rope in new condition will provide a restoring force of 700 pounds, or 10 per cent of the ultimate strength. A 20 per cent elongation would result in a restoring force of 2,000 pounds, which is undesirably large in most eircumstances, and should be avoided by proper design. The maximum force available is the sum of the maximum wind drag and the additional force exerted on the pennant by a displacement of the surface float over a distance equal to about 25 per cent of the wave length. In making the calculation, it is best to assume that the maximum current drag exists at all times. Details of the calculation of the restoring forces are given in the Appendix. 
For surface floats at Scripps we have used glass-reinforced plastic skiffs of various sizes up to 16 feet long, and catamarans (see Appendix). A 20-foot painter ending in a ring is secured to the stem of the skiff (fig. 4). This connects with the main pennant, as explained later.

\section{Spar Buoys}

A nonresponding spar buoy has many advantages, but it is not suitable for use with a long-lived taut-wire mooring. A nonresponding spar is one whose natural period of vertical oscillation is much longer than that of any expected wave of significant height. For a hydrometer-shaped float or a spar restrained by an elastic pennant, a damped spring-mass calculation must be made.* Resonance, which is obviously a condition to be avoided, will occur with a lightly restrained cylindrical spar whose submerged length is $\mathrm{L}_{0} / 2 \pi$. If the pennant between the spar and the submerged float leads away horizontally at the surface, it will be subject to severe flexing and abrasion at the point of attachment to the spar. If it is vertical, then when it is slack during calm weather it will foul the submerged float. The principal difficulty with the spar buoy, however, is that its motion in a seaway is incompatible with that of any conventional craft that might try to handle it or come alongside.

\section{Pennants and Instrument Lines}

The pennant is the member of the mooring assembly which connects the surface float to the submerged float.

The surface pennant to a responding float (skiff) either must lead almost horizontally away from the float, or, if nearly vertical, must be highly elastic. This is because, when the float is subject to whitecaps or combers, its vertical downward accelerations approach that of gravity. Hence, any vertical string depending only upon gravity forces for tension will slack and jerk in a way that will greatly shorten its life, if, indeed, it survives at all. In addition, the skiff does not respond well to a vertical load near the bow.

Both types of pennants are in use. A common pennant is a nylon float line that tends upward in a floating catenary. In slack weather this pennant (with a scope of about 2.0) floats forward of the surface float and greatly increases the possibility that the mooring will be run down by a passing vessel. This danger is intensified by the fact that in slack weather the visual and radar detection range of vessels is increased so that curious passing navigators are more likely to investigate.

The instrument line can then be lowered independently over the stern of the float, utilizing a section of shock cord to provide elasticity. This system is limited to instrument lines that are shallower than the submerged float; to weather situations that are constant, such as the trades; and to short-period installations. (Otherwise the pennant and the instrument line will foul.)

Experimental vertically tending elastic pennants are now under test. The pennant is made of fabric-covered rubber shock cord with the instrument line

\footnotetext{
* It should be kept in mind in this calculation that the "damping pot" (i.e., the sea water) is not fixed as in the usual model, but is oscillating.
} 


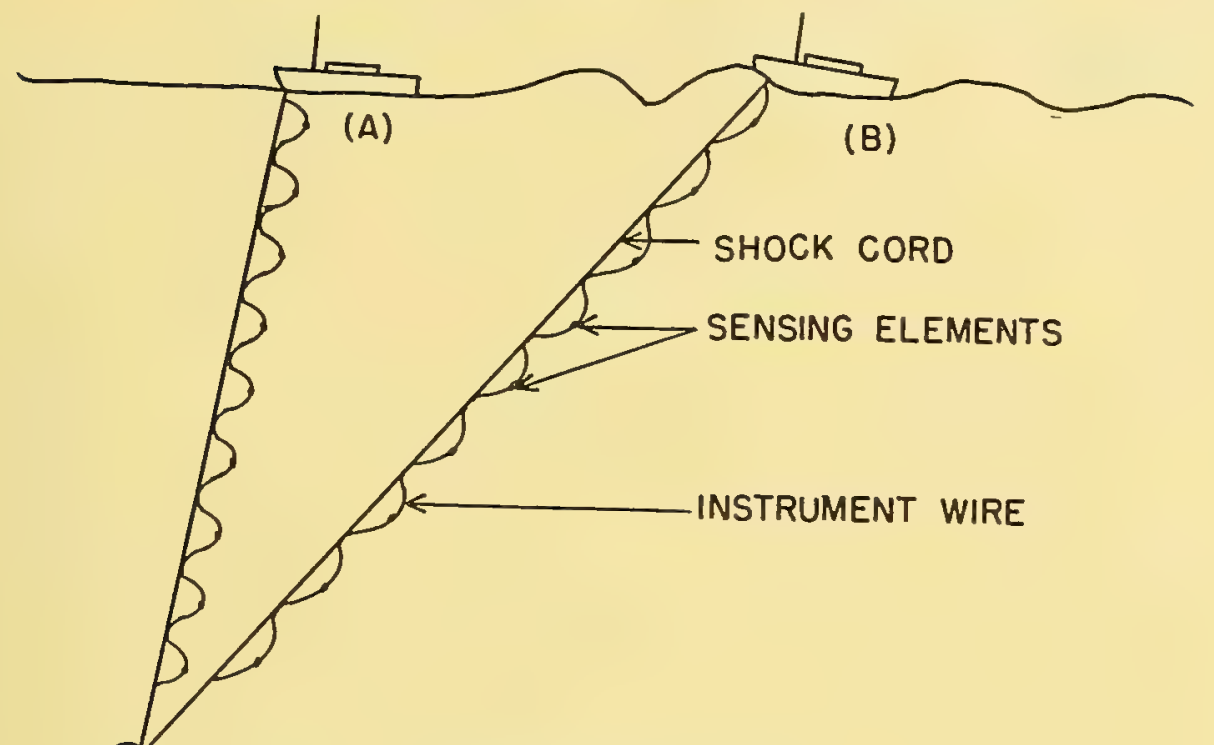

SELF REELING SUBMERGED FLOAT

MOORING WIRE

(A) Position in slack weather.

(B) Position in heavy weather.

Fig. 5. Shock-cord mooring pennant.

married to it at intervals in S-shaped loops, as in figure 5. An advantage of this latter system is that the terminations of the instrument line remain at approximately constant depths as the scope increases. In this system a specially designed submerged float (see below) is necessary to permit recovery of the instrument line. The shock cord is designed to be under considerable tension when vertical, and to extend to maximum allowable tension at the limiting weather conditions. The design of the elastic pennant is much simpler than that of the floating pennant, as the restraint history with displacement is readily calculated.

\section{The SubMerged FloAT}

The submerged float must provide sufficient buoyancy to support the mooring wire and to result in adequate tension at the anchor. (Adequate tension is discussed later.) Subsurface floats have usually consisted of spherical steel tanks with a diameter of approximately 3 feet, and a wall thickness of $1 / 8$ inch or more (commercial butane tanks and cylindrical steel tanks have been used). In use, subsurface floats are normally pressurized to about the ambient pressure at their 
proposed depth. An unpressurized spherical steel tank, 34 inches in diameter and with a wall thickness of $7 / 32$ inch, has been successfully pressure-tested to a depth of 1,500 feet. The drag of the submerged float is small in comparison with the other drags of the system, and streamlining has not been contemplated. Streamlining involves an asymmetry and an orientation in the system which are disadvantageous where any wave action occurs, because the float will continuously rotate.

An interesting modification of the spherical buoy, which will pay out additional wire as soon as the design tension of the pennant is reached, has been used. This self-reeling submerged float functions as shown in figure 6 . The surface line is wound around the large reel of diameter $D_{1}$, and the bridle is wound around two smaller reels of diameter $D_{s}$ on opposite sides. All three spools have the same axis of rotation and are fixed relative to one another. When the tension in the pennant exceeds $\left(\mathrm{D}_{\mathrm{s}} / \mathrm{D}_{1}\right) \times \mathrm{B}$ (buoyancy), the float winds down the bridle releasing a length of wire $D_{1} / D_{s}$ times the distance traveled until the stress in the pennant falls below $\left(D_{B} / D_{1}\right) \times B$ or the buoy is two-blocked against the bridle.

The advantages of mooring with such a float are as follows: the instrument line may be one with the mooring line, thus eliminating the undesirable situation of two lines over the side; the instrument mooring line may be retrieved for inspection, servicing, or replacement by merely heaving in; the additional scope necessary to accommodate extreme sea conditions is provided; and a nearly vertical pennant line may be used, thus greatly reducing the hazard caused by surface traffic. This self-reeling float is normally used in conjunction with an elastic pennant (fig. 5), which is designed to accommodate the wave-induced displacements of the surface buoy. Therefore the self-reeling float needs only to accommodate the larger deflections caused by extremes of wind and current.

In selecting the design depth for the submerged float, the following may be among the criteria: (1) the submerged float should be deep enough to escape being run down; (2) it should be deep enough to minimize the effects of surface waves; (3) it should be at the greatest depth at which observations are desired (fig. 5); (4) it should be at a depth that divers can reach; (5) it should be deep enough to escape surface currents, that is, below the thermocline; and (6) it should be deep enough to escape surface fouling. The depth most often used at Scripps has been 150 feet.

\section{Mooring Cables}

One of the technical problems of anchoring or of installing a mooring in deep water is shown in figure 7. Here is depicted the ultimate tensile strength necessary for a steel wire of uniform cross section to be used at any depth in the sea when bearing an additional load equal to its own weight. (Also, an allowance must be made for weakening of the wire by handling and by corrosion.) Figure 7 also shows the percentage of the ocean area at a depth less than the ordinate. Using this allowable-depth criterion, it is apparent that wire of an ultimate tensile strength of 100,000 psi may safely be used to a depth of about 1,700 fathoms, or in about 30 per cent of the oceans. A wire of an ultimate tensile strength of 180,000 psi, however, may be employed to 3,000 fathoms, or in 99 per cent of the 


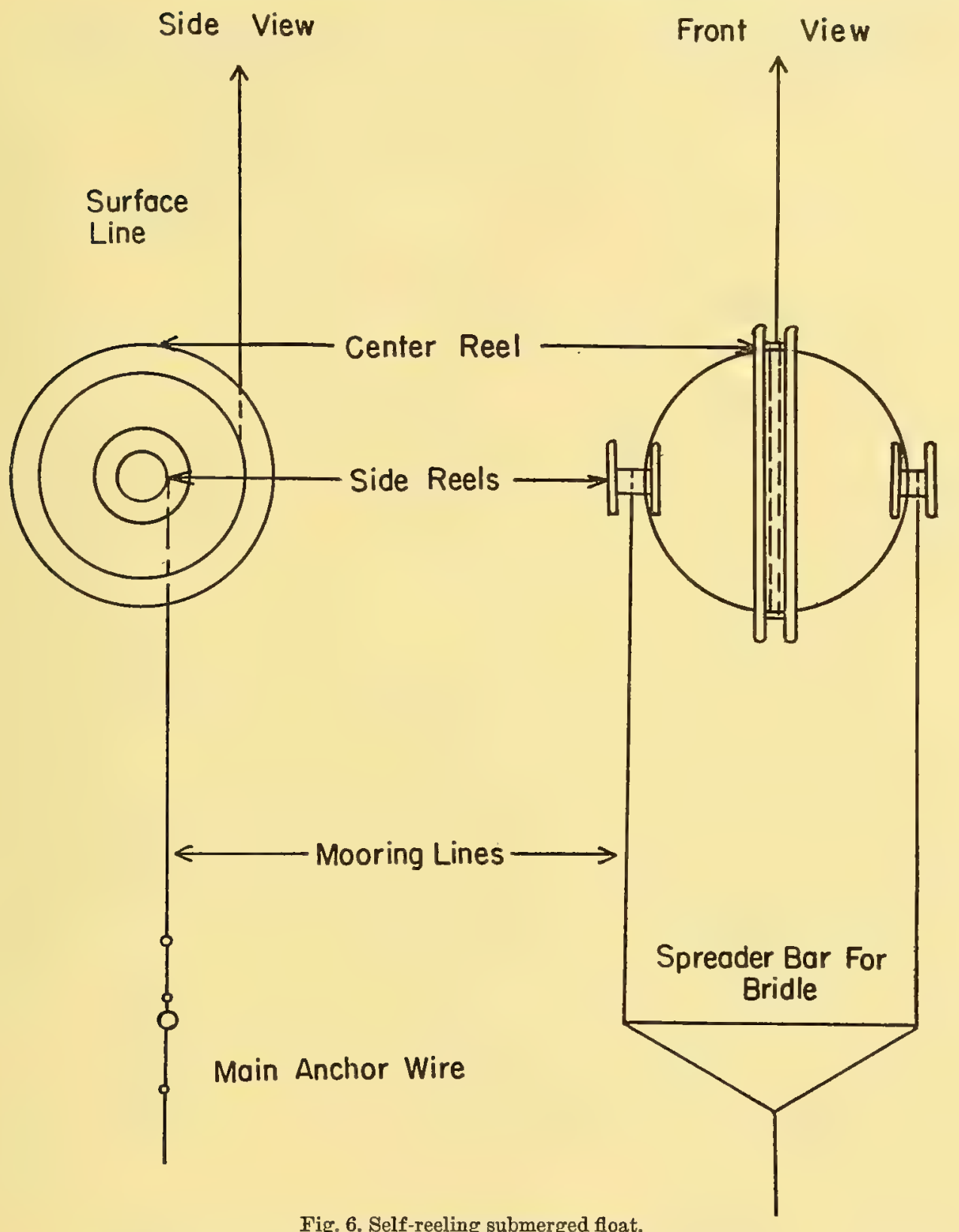

Fig. 6. Self-reeling submerged float.

sea area. The wire used in recent work had an ultimate tensile strength of about 260,000 psi.

The above relates solely to the quasi-static stresses produced in lowering the mooring wire. Other dynamic stresses become important as soon as the anchor reaches bottom. The area presented by such a wire to the horizontal drag force may be quite large. For example, 15,000 feet of 1/8-inch wire presents about 156 
square feet of form drag area, or about that of a large barge. Fortunately, water velocities at great depths are low, and hence the total horizontal drag force over most of the length of wire is small.

ULTIMATE TENSILE STRENGTH OF WIRE P.S.I.

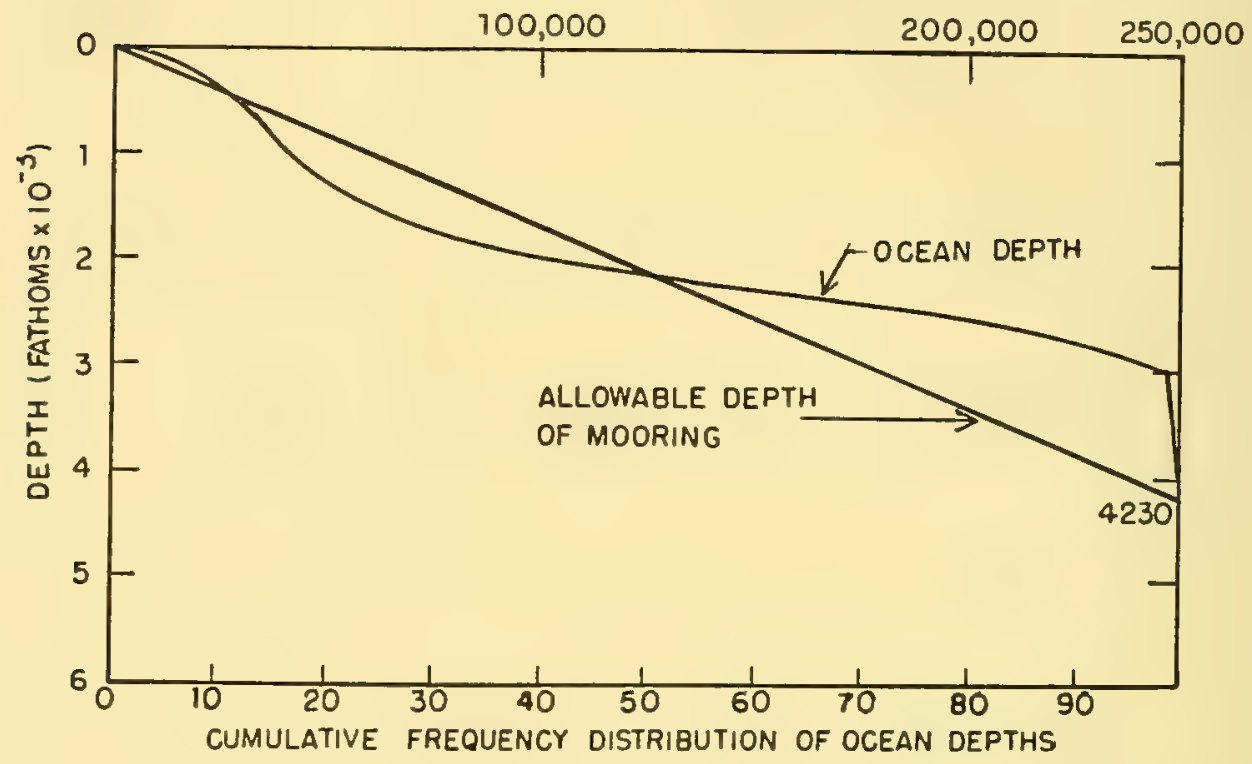

Fig. 7. Ultimate tensile-strength requirement.

As horizontal forces increase, wire with a greater ultimate strength must be used to limit excursion and dip of the system. Hence the strength/drag ratio of the wire is important. For wires of the same specific gravity and construction this may be expressed as follows:

where

$$
T=(1 / k) s(\pi / 4) t^{2}
$$

$\mathrm{T}=$ maximum allowable tension on the wire

$\mathrm{k}=$ safety factor

$\mathrm{s}=$ ultimate strength of wire in psi

$\mathrm{t}=$ diameter of wire in inches

$$
\mathrm{D} \sim \mathrm{t}
$$

where

$\mathrm{D}=$ drag force on the wire in pounds

$$
\left.\mathrm{R}=\mathrm{s} \pi \mathrm{t}^{2} / 4 \mathrm{D} \text {, the strength/drag ratio ( } \mathrm{T} / \mathrm{D}\right)
$$

Therefore

$$
R \sim s(\pi / 4)\left(t^{2} / t\right) \text { or }
$$

$$
\mathrm{R} \sim \mathrm{st}
$$

The higher the strength/drag ratio, the more nearly vertical a mooring may be made for a given current profile. 
To compare the configuration of moorings using lines of different materials requires consideration of their weight in water. For taut-wire moorings of small inclination, the weight (or buoyancy) may be considered to act in the same direction as the maximum allowable tension. Thus:

where

$$
\mathrm{T}=1 / \mathrm{k}\left(\mathrm{s}[\pi / 4] \mathrm{t}^{2}-62.4[\rho-1.024] \mathrm{L}[\pi / 4]\left[\mathrm{t}^{2} / 144\right]\right)
$$

$\mathrm{L}=$ length of wire in feet

$\rho=$ specific gravity of wire

1.024 = specific gravity of sea water

$$
\mathrm{D} \sim \mathrm{t}
$$

Hence if $\mathrm{R}^{\prime}$ is the tension/drag ratio

$$
\begin{aligned}
& \mathrm{R}^{\prime} \sim \mathrm{st}-0.434 \mathrm{Lt}(\rho-1.024) \\
& \quad \sim \mathrm{t}(\mathrm{s}-0.434 \mathrm{~L}(\rho-1.024))
\end{aligned}
$$

\begin{tabular}{|c|c|c|c|c|}
\hline Material & $\begin{array}{l}\text { Ultimate strength (B) } \\
\text { (in psi) }\end{array}$ & $\begin{array}{c}\text { Specific } \\
\text { gravity }(\rho)\end{array}$ & $\begin{array}{l}\text { Thickness (t) } \\
\text { (in inches) }\end{array}$ & $\begin{array}{l}\text { Relative weight per } \\
\left.\text { unit length (ot }{ }^{2}\right)\end{array}$ \\
\hline Piano wire............. & 325,000 & 8 & 0.12 & 0.12 \\
\hline Wire rope ${ }^{*} . . .$. & 125,000 & 8 & 0.39 & 1.20 \\
\hline Nylon............ & 30,000 & 1 & 0.93 & 0.87 \\
\hline
\end{tabular}

TABLE 1

COMPARISON OF CABLES

* The wire rope used for this example is airplane control cable which is unsuitsble on other counts besides its un favorable tension/drag ratio.

Table 1 compares lines of different material and construction having the same tension/drag ratio, namely $R^{\prime}=32,000$ for a length of 20,000 feet. Thus to have the same tension/drag ratio as $1 / 8$-inch piano wire, the airplane control cable would weigh 10 times as much in air, and the nylon line 7 times as much.

It is apparent that the problem of high stresses in lowering could be ameliorated by use of a mooring line whose density is closer to unity. Some experimental installations have been made with taut nylon rope (see Appendix).

For this most critical component-the 2 to 3 miles of mooring wire-of deepocean taut-moored systems, two types of wire have been used: a solid electrolytically galvanized steel wire and a stranded $(1 \times 7$, long lay) electrolytically galvanized steel wire. The solid wire size varies from a 0.082 -inch diameter to a 0.120 -inch diameter. The stranded wire size varies from a 0.123 -inch diameter to a 0.200 -inch diameter.

Stations using the special stranded wire with a tensile strength of 260,000 psi have been installed. Experience indicates that such stations have a life expectancy equal at least to that of stations using a solid wire. A few well-spaced butt welds may be used in fabricating the individual strands, for the loss in strength is reduced by the number of strands. There are several advantages in using stranded wire. The stranded wire will take a smaller radius bend than the solid wire; it is simpler to unspool because of a reduced tendency to "cut in" to the underlying layers; it is possible to make the stranded wire in extremely long continuous 
lengths without special processing; and it has satisfactory ratios of tension/drag and strength/weight.

Sections of solid wire recovered from actual installations after five months of use, and a section of 0.123 -inch, $1 \times 7$ strand wire recovered after three months of use, showed no visible signs of deterioration. Samples of wires fastened to a test board and not under stress were recovered after fifteen months. Here the sections of solid wire showed clearly visible signs of deterioration, rather severe in some instances, whereas the stranded-wire samples showed no visible signs of deterioration. It is believed that some of the water-resistant lubricants used on stranded wire by manufacturers are of real value in retarding deterioration. The U.S. Navy Electronics Laboratory Materials Engineering Section has been helpful in recommending suitable lubricants.

\section{ANCHORS}

High-density anchors are desirable because their small dimensions for a given weight permit handling without excessively long booms or davits. Also their high rate of lowering in water allows a mooring to be laid in a short time, thus avoiding drifting off station.

Various kinds of anchors have been used. Some have been solid steel cubes with pad eyes welded on top and bottom and some have been ordinary railroad-car wheels. As moorings increase in size and complexity, a more sophisticated design of anchor will be required if the size of the mooring wire is to be kept at a minimum. For our installations, gravity anchors have been designed so that the net vertical reaction against the bottom is equal to at least 1.4 times the sum of the expected horizontal forces. Or,

where

$$
\mathrm{W}_{\mathrm{A}}+\mathrm{W}_{\mathrm{W}}-\mathrm{B}=1.4 \mathrm{~F}_{\mathrm{H}}(\text { fig. 8) }
$$

$\mathrm{W}_{\mathrm{A}}=$ weight in sea water of anchor

$\mathrm{W}_{\mathrm{W}}=$ weight in sea water of wire below submerged float

$\mathrm{B}$ = buoyancy of submerged float

$\mathrm{F}_{\mathrm{H}}=$ horizontal component of forces at the anchor

$=\mathrm{F}_{\mathrm{M}} \cos \theta$, where $\mathrm{F}_{\mathrm{M}}$ is the tension on the mooring wire

This has led to satisfactory performance on a relatively flat bottom. For a bottom with a slope $\phi$, the frictional force $F_{F}$ required may be expressed as

$$
\mathrm{F}_{\mathrm{F}}=0.7\left(\mathrm{~W}_{\mathrm{A}}-\mathrm{T}\right) \cos \phi
$$

where

$$
\mathrm{T}=\mathrm{B}-\mathrm{W}_{\mathrm{W}}=\mathrm{F}_{\mathrm{M}} \sin \theta
$$

For equilibrium the sum of forces $\mathrm{F}$ acting parallel to the slope must equal zero, or

$$
\begin{gathered}
\mathrm{F}=\mathrm{T} \sin \phi-\mathrm{W}_{\mathrm{A}} \sin \phi-\mathrm{F}_{\mathrm{H}} \cos \phi+0.7\left(\mathrm{~W}_{\mathrm{A}}-\mathrm{T}\right) \cos \phi=0 \\
\mathrm{~W}_{\mathrm{A}}-\mathrm{T}=\mathrm{F}_{\mathrm{H}} /(0.7-\tan \phi)
\end{gathered}
$$

With these assumptions a simple gravity anchor becomes impractical on bottoms with slopes exceeding about 20 degrees, and anchors with hooks, flukes, or grapnels must be used. Unless other considerations are overriding, it is best to anchor moorings in flat areas. Small-scale bottom features may be ignored to the extent that the 
displacement of the system eaused by an anchor gradually sliding down to a local low is negligible. On extensive steep slopes it is difficult to anchor a mooring at a selected depth, and such sites are doubly undesirable.

\section{FitTings}

The galvanized wire rope used between mooring wire and anchor and between mooring wire and submerged float usually terminates in a large galvanized thimble secured with Nicopress fittings. Nylon rope usually terminates in a round plastic thimble and a hand splice which permits the thimble to rotate without damage to the eye when under tension. A special wire terminal clamp (fig. 9) has been de-

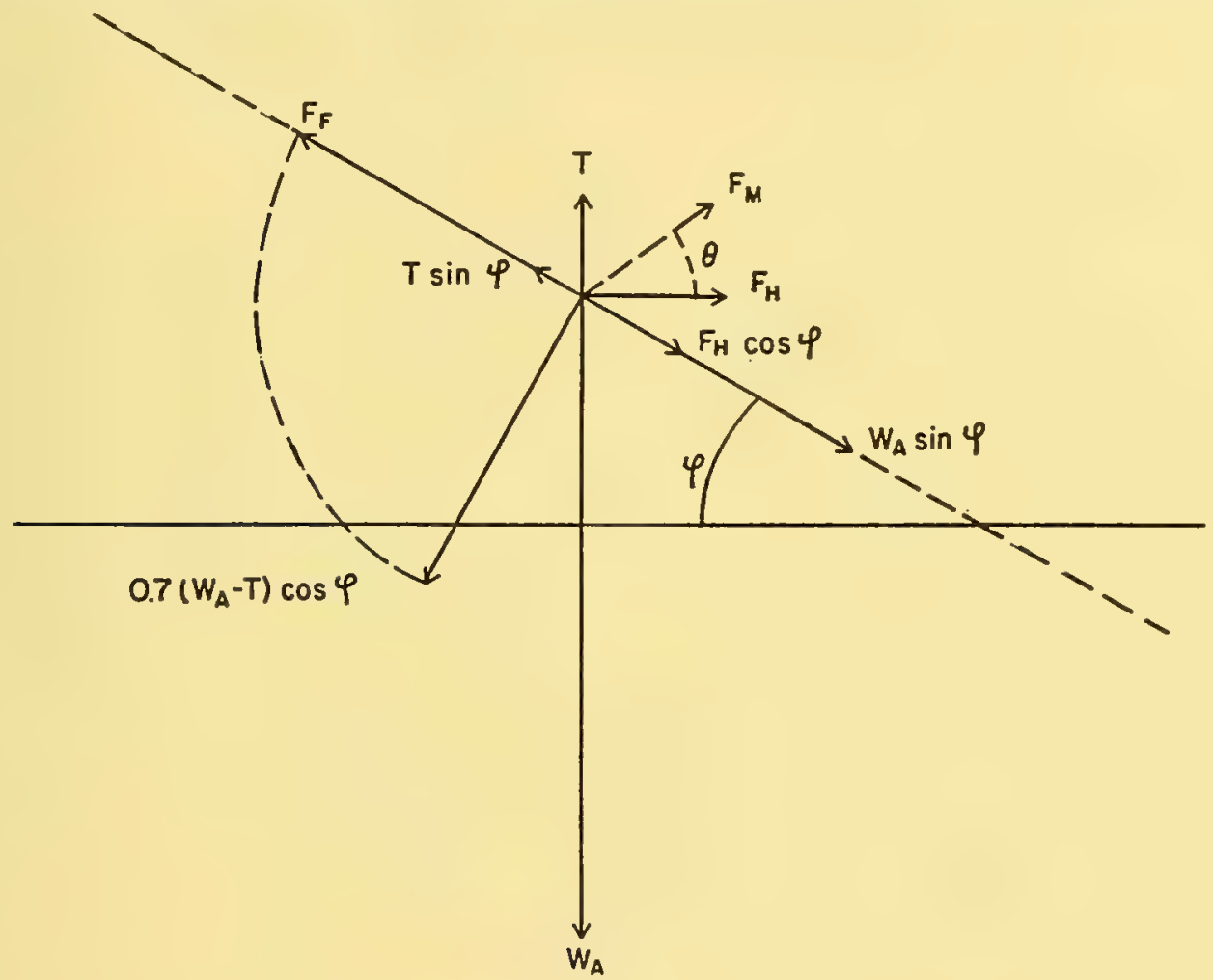

Fig. 8. Forces on anchor on sloping bottom.

signed for securing the piano wire to a shackle. In use it is advisable to insulate the clamp from the shackle by a micarta sleeve and washers and to paint the clamp with plumbers' black mastic just after it is in place.

\section{Bottom-DETeCting Devices}

The anchor is provided with a 150 -foot pennant carrying a device that will give warning when it touches the bottom. The bottom-detecting device, on contact with the bottom, allows a solid steel piston, weighing about 30 pounds and fitted with a sharp fluted point, to fall and puncture a small glass ball ( 3 inches in diameter) 

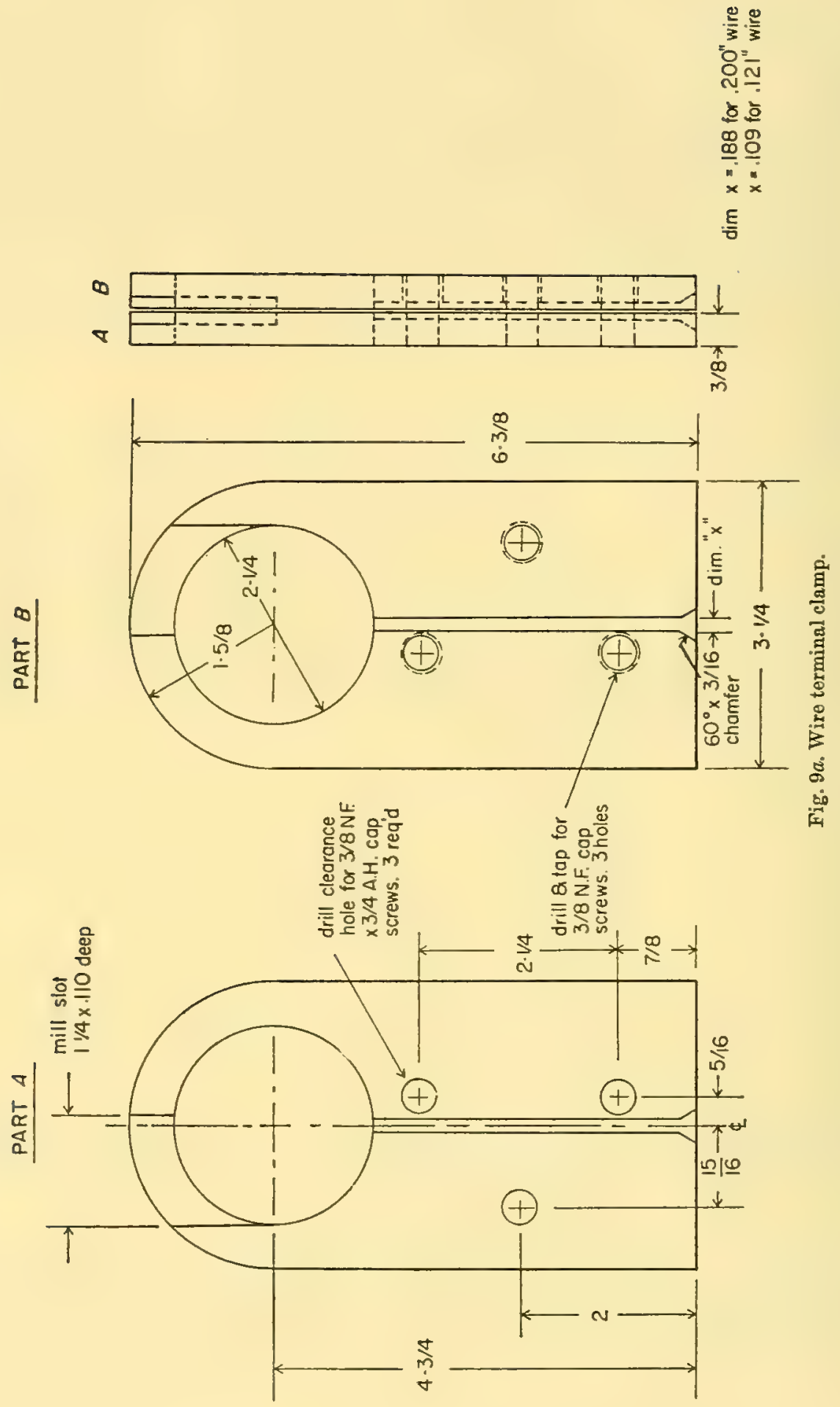


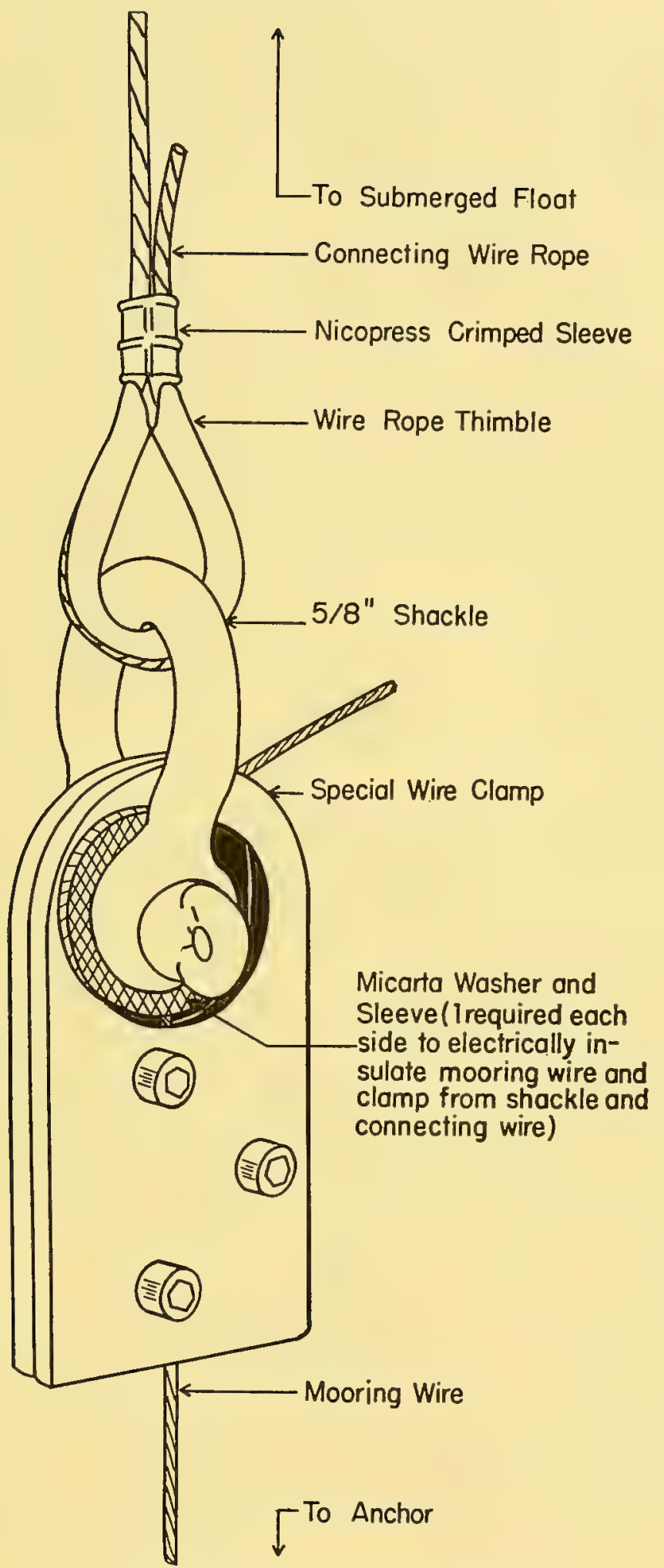

Fig. 9b. Typical mooring-wire termination. 
which rests on another mass of steel. The rupturing of the glass ball causes a violent implosion that is audible at the surface through the echo sounder. This hammer-and-anvil principle gives a much more satisfactory signal than did earlier bottom-detecting devices that did not employ the fixed steel mass as a pedestal for the glass ball.

When desirable, because of bottom topography or other conditions, anchor flukes are welded to the bottom-detecting device, so that the device, after having served its purpose as a bottom detector, becomes a drag anchor.

\section{SYSTEM DESIGN}

The design of the mooring must stem from a knowledge of the physical forces of the environment acting upon the components in a geometry determined by the same interaction. Hence the design cannot be uniquely expressed as any simple function of the parameters. Rather, the various components may be provisionally selected by simplified criteria, the geometry of the assemblage examined, and adjustments made. A workable method for doing this is outlined below and is discussed in more detail in the Appendix. The design is carried out step by step as follows.

1) The mean or modal surface current, vertical current profile, wind velocity, and depth of water are measured or estimated. Estimates are also made of extremes of surface current, wind, and wave height. The magnitudes of all these phenomena may depend on the season and on the length of time that the mooring will be in place.

2) The wind drag and the water drag on the surface unit are calculated.

The wind drag on the vessel or skiff may be computed for any impact angle once the drag area has been determined. The wind drag area of the hull, the superstructure, the masts, and so forth, above the water line may be taken from the vessel's prints, or perhaps estimated. A convenient formula for computing the wind drag is

where

$$
\mathrm{F}=\mathrm{KA} \nabla^{2}
$$

$\mathrm{F}=$ force in pounds

$K=$ constant $=0.0025$ (a value as high as 0.004 is often used for more complicated shapes such as that of a large ship)

$\mathrm{A}=$ wind drag area of vessel in square feet

$\mathrm{V}=$ speed of wind in miles per hour

Conversion factors for velocity in different units are given in table 2.

TABLE 2

Velocity Conversion Factors

\begin{tabular}{|c|c|c|c|c|}
\hline Velocity & St. $\mathrm{mi} / \mathrm{hr}$ & Knots & $\mathrm{Ft} / \mathrm{Bec}$ & $\mathrm{Ft} / \min$ \\
\hline 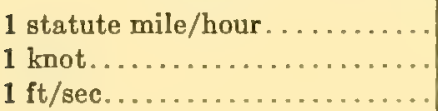 & $\begin{array}{l}1 \\
1.15 \\
0.682\end{array}$ & $\begin{array}{l}0.868 \\
1 \\
0.592\end{array}$ & $\begin{array}{l}1.47 \\
1.69 \\
1\end{array}$ & $\begin{array}{r}88.0 \\
101 \\
60\end{array}$ \\
\hline
\end{tabular}


The water drag or hull resistance of a vessel is broadly considered in two parts: (1) the surface or skin resistance and (2) the wave-making resistance.

The surface resistance is computed by using the conventional formula,

where

$$
R_{\mathrm{B}}=\mathrm{f}_{\mathrm{B}} A \mathrm{~V}_{\mathrm{K}^{1.83}}
$$

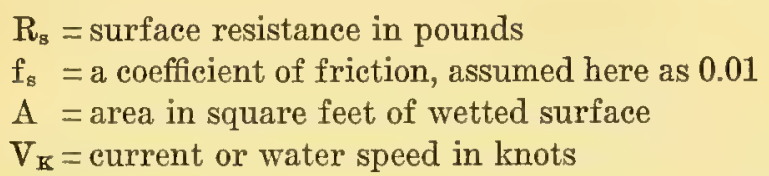

The wave-making resistance is not normally computed, but for our purpose here it may be assumed to approximate 30 per cent of the total hull resistance. For ships of usual design at moderate speeds (as when anchored in a current) this approximation is frequently used.

3) The weight and the horizontal drag of the submerged elements are calculated. The chief components are the mooring wire and the submerged float, which is selected to have a net buoyancy equal to about 60 per cent of the ultimate strength of the wire.

When the current structure (vertical distribution of current) at the mooring site is known or assumed, the drag force on the mooring wire and components may be computed from the formula,

where

$$
\mathrm{F}=\mathrm{C}_{\mathrm{d}} \Delta \mathrm{V}^{2}
$$

$\mathbf{F}=$ drag force in pounds

$\mathrm{C}_{\mathrm{d}}=\mathrm{a}$ coefficient of $\mathrm{drag}$ which may vary from, say, 0.3 to 1.5 , but which, for first approximations, we assume to be 1.1.

$\mathrm{A}=$ area of wire in square feet

$\nabla=$ current speed in feet per second

If instrument strings are suspended over the side, the added drag may be computed by using the above formula. If the current is not uniform from surface to bottom, the total force will be obtained by appropriate integration, or forces may be applied as a series of point loadings for several increments of depth.

4) The angles of the wire at the submerged float and at the anchor are estimated from the relationships:

$\gamma_{1}=$ wire angle from the vertical at the submerged float

$\mathrm{F}_{\mathrm{H}_{1}}=$ total horizontal drag of submerged float and array above it

$\mathrm{B}$ = buoyancy of submerged float

$$
\gamma_{1}=\tan ^{-1}\left(\mathrm{~F}_{\mathrm{H}_{1}} / \mathrm{B}\right)
$$

$\gamma_{2}=$ wire angle from the vertical at the anchor

$\mathrm{W}=$ weight of wire in water

Then

$\mathrm{F}_{\mathrm{H}_{2}}=$ total horizontal drag on entire system below submerged float

$$
\gamma_{2}=\tan ^{-1}\left(\mathrm{~F}_{\mathrm{H}_{1}}+\mathrm{F}_{\mathrm{H}_{2}}\right) /(\mathrm{B}-\mathrm{W})
$$

5) A preliminary estimate of dip and exeursion may now be made by fitting between these two angles a circular are having a length equal to the length of cable between the submerged float and the anchor, as follows (fig. 10): 


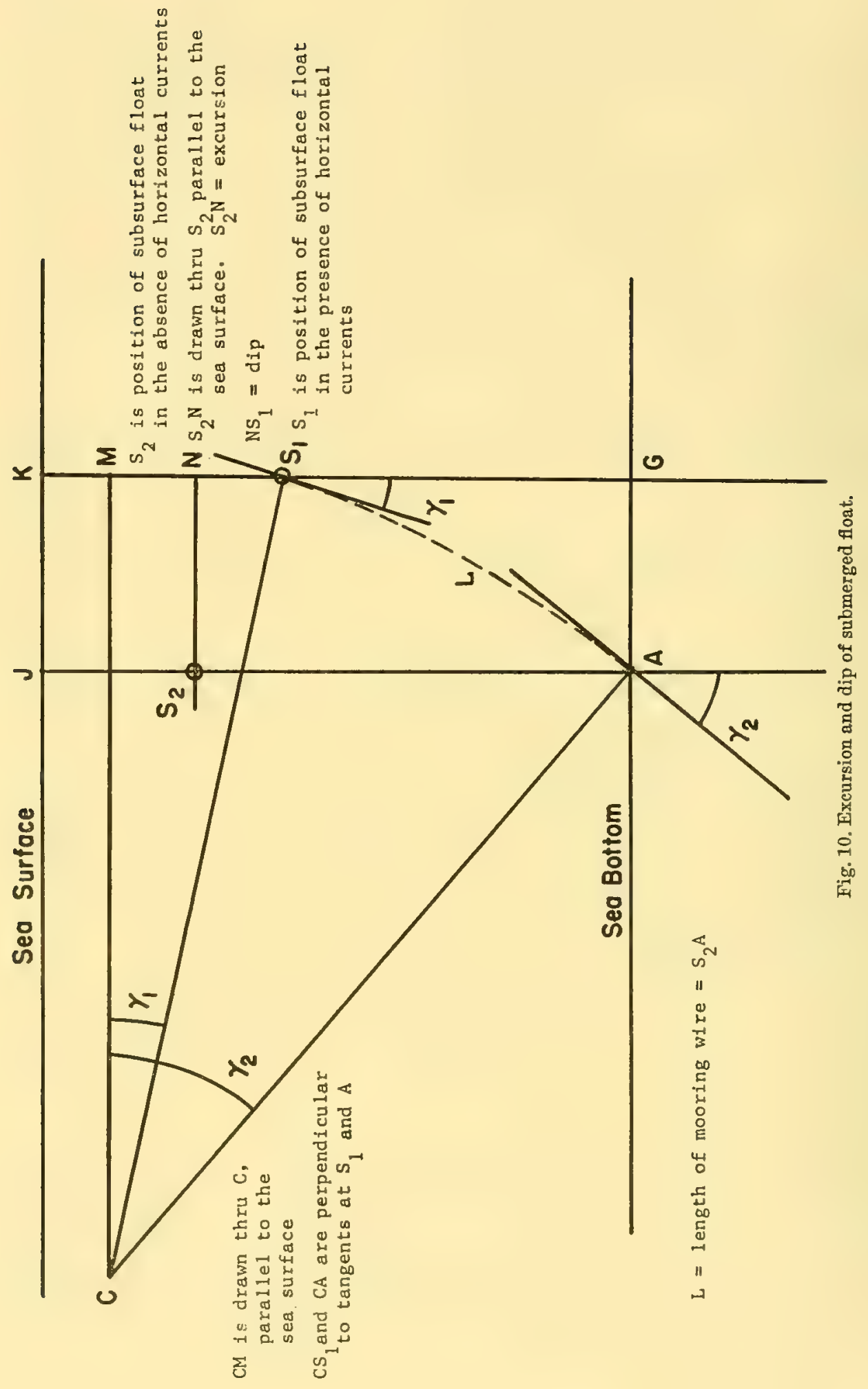




$$
\mathrm{D}=\left(360 \mathrm{~L} / 2 \pi\left[\gamma_{2}-\gamma_{1}\right]\right)\left(\sin \gamma_{2}-\sin \gamma_{1}\right)-\mathrm{L}
$$

where

$$
\mathrm{D}=\operatorname{dip}
$$

$\mathrm{L}=$ length of wire between submerged float and anchor;

and

where

$$
\mathrm{E}=\left(360 \mathrm{~L} / 2 \pi\left[\gamma_{2}-\gamma_{1}\right]\right)\left(\cos \gamma_{1}-\cos \gamma_{2}\right)
$$

$$
\mathbf{E}=\text { excursion }
$$

The excursion is somewhat overestimated by this procedure and the dip is somewhat underestimated.

6) If the estimates of dip and excursion are satisfactory, the design may proceed. If they are too large, buoyancy may be increased moderately, say by 10 per cent, or other adjustments may be made. If these measures do not suffice, the size or the strength of the wire selected must be increased and the calculation must be repeated. This increase may be judged by selecting a wire with a strength/drag ratio that is larger than the first trial by the ratio of the calculated excursion $\left(\mathrm{E}_{1}\right)$ to the desired excursion $\left(E_{2}\right)$. That is, $R_{2}=R_{1}\left(E_{1} / E_{2}\right)$, where $R_{1}$ and $R_{2}$ are the strength/drag ratios, respectively, of the first and the second trial wires. As the recalculated float and other parameters will seale proportionally to $R$, this second trial should be adequate. Note that simply increasing the size of the wire increases R.

7) The geometry of the mooring should now be analyzed with greater exactitude. This may be done by the graphic method illustrated in the Appendix. In this computation it may be advisable to include factors that have previously been neglected, such as

Water drag on the mooring pennant

Water and wind drag on auxiliary floats

Water drag on any instrument strings

Buoyancy of auxiliary floats

Buoyancy of the surface float (instrument skiff, etc.)

In connection with the above computations, the basic coefficients of flow and the development of simplified formulas are discussed in the Appendix.

8) As soon as the design is satisfactory from the standpoint of excursion and dip, the minimum anchor weight is determined by the criteria previously discussed.

9) The pennant length and characteristies are now chosen to afford satisfactory performance in combers, as explained earlier. This is carried out by determining the geometry of the mooring under highest expected wind stress without current stress. Then, assuming that the submerged buoy remains fixed, the pennant is extended horizontally to 20 per cent of $\mathrm{L}_{0}$ of the critical wave. The force increase should be such that $\left(V_{t}+V_{u}\right) / 2=C_{0} / 12$, where $V_{t}$ is the velocity of the surface float under a force equal to the wind stress, $V_{u}$ is the velocity of the surface float under the increased force of the extended pennant, and $\mathrm{C}_{0}$ is the phase velocity of the wave.

10) The calculation in (9) above is repeated, using the configuration of the 
mooring for highest wind and current stress, and the stress is examined when the pennant is extended horizontally 20 per cent of $\mathrm{L}_{0}$, as before.

11) The lift induced by the pennant may now be entered into the calculation, if necessary.

In the final design several additional requirements have been found advisable.

Two provisions against failure of the submerged float are: (1) the surface float is given additional buoyancy adequate to support both the cable and the submerged float if water-filled, and (2) the main mooring cable is terminated at a distance above the anchor somewhat greater than the distance the submerged float would sink. In this lowest portion we use a suitable flexible wire rope, such as $3 / 16^{-i n c h, ~} 3 \times 19$ improved plow steel. Aircraft cord, which is more susceptible to kinking and abrasion, is not suitable. This is to prevent the brittle mooring wire from dragging on the bottom in the event of flooding of the submerged float.

\section{ACKNOWLEDGMENTS}

This work was undertaken by the Division of Marine Resources at the Scripps Institution of Oceanography and was supported by the Office of Naval Research, the Marine Life Research Program, and the Tuna Oceanography Research Program. Acknowledgment is also made to Cecil D. Jennings, Robert P. Huffer, Lewis W. Kidd, and Eskil Holt for their assistance in carrying out this development and for their many contributions. The Marine Life Research Program is part of the California Cooperative Fisheries Investigations, sponsored by the Marine Research Committee of the State of California. 


\section{APPENDIX}

The following relates to the installation, the servicing, and so forth, of the mooring shown in figure 1. This should serve as a guide for taut-moored systems placed by ships in general.

\section{Shipboard Installations}

Certain basic equipment is required for the proper and safe handling of mooring components on board ship regardless of the number of moorings to be installed or the frequency with which they will be serviced or retrieved. These latter factors, however, may well determine the permaneney of installations on board and the elaborateness of the equipment.

The basic special equipment required consists of a suitable winch for spooling and controlling the wire, a suitable davit for handling the wire and the attached gear over the side, a suitable platform adjacent to the davit (and at main deck level) from which to work, and launching skids adjacent to the work platform. These, together with the equipment normally available, including a boom and two or three conveniently located gypsy heads, constitute the essential installed handling equipment.

\section{Accessorx Handing Equipment}

The required accessory handling equipment includes a suitable metering sheave with remote indicator and a chain fall of about 1-ton capacity. Additional sheaves and fair-leads should be supplied as necessary for the mooring wire and the handling lines. A retrieving ramp may be advisable if many skiffs are to be handled.

\section{Spooling Winch}

A special winch capable of paying out the mooring wire directly from the factory spool would be desirable and would save the time otherwise required for respooling the wire onto a winch drum. The wire cannot ordinarily be spooled taut enough on the factory spool, and the "cutting-in" of the wire makes direct pay-out hazardous. However, standard hydrographic winches, such as the Markey type DES-7, fifteen horsepower, have been used very satisfactorily for this purpose. The only modifications that may be required to the hydrographic winches are (1) to insert wooden fillers about the drum to increase its diameter and thus avoid damage to the wire if it otherwise would be bent about too small a radius, and (2) to change the gears in the level wind mechanism as necessary to provide for proper spooling of the wire when its size is greatly different from that of the hydrographic wire.

As even an experienced crew may take two hours to spool 16,000 feet of wire on a winch, it is important to perform this task before arriving on station.

\section{WORK DAVIT}

The work davit may be a reinforced hydrographic davit. The davit must accommodate (1) the remote-reading metering sheave (Kahl type or similar), which 
handles the mooring wire, (2) a snatch block with manila tag line running to a powered gypsy head, and (3) a 1-ton chain fall. This arrangement provides the necessary versatility for handling the various pennants, the anchor, the floats, and similar gear.

\section{Work Platform}

An overside work platform adjacent to the davit, and preferably flush with the main deck, is required for attaching elements to the wire and for handling the heavier weights over the side. The details will vary from ship to ship, but the platform should be of reasonable proportions and, when in use, rigidly supported. If it is to be used frequently, it should be designed so as to form part of the gunwale when not in use, and either to swing out or to drop down when in use. This provides a clear, deck-level access to the platform when in the working position.

\section{SKIFF-RETRIEVING RAMP}

A skiff-retrieving ramp designed to permit the vessel to bring skiffs on board for scrvicing is very useful. Previous experience has shown that servicing an instrument skiff from a small work boat is a difficult and time-consuming procedure. $\mathbf{A}$ skiff-retrieving ramp built at Scripps was approximately 26 feet long, 4 feet wide, and slightly cradled to accept the keel of the skiff. Rails designed to prevent the skiffs from falling out of the ramp in the event of sudden yawing were added. The ramp was fabricated of standard 2- and 3-inch pipe, and was attached to the stern of the vessel by a heavy-duty ball-type trailer hitch. Two outriggers projected over the stern, one on each side of and adjacent to the ramp, to support and retrieve the ramp. Under way, the ramp was carried in a horizontal position. In use, the outer end was lowered to the water by means of cables from the outriggers. The inboard ends of the cables were led directly to powered gypsy heads.

\section{Navigational and ACCESSORY EquIPMENT}

The installing and servicing ressel will usually need to know its position within very close limits, and therefore it should be provided with all reasonable aids to navigation. When trying to locate a small skiff in the open ocean, a radar is essential. An echo sounder, Edo AN/UQN-13 or equivalent, is used to measure the depth and, in conjunction with the bottom-detecting device, to hear the impact of the mooring on the bottom. A take-off from the earphone jack on the echo sounder may be led back to an amplifier on deck and then to a loud-speaker near the work area, thus enabling the mooring crew to hear the signal on bottom contact.

\section{Mooring Techniques \\ PREPARATION FOR LAYING THE MOORING}

Assuming that the vessel is in the area of interest with all gear on board, preparations for laying the mooring consist mainly of assembling the various components to be used in the work area on the fantail (or other area, depending on the vessel layout). The wire rope and the nylon pennants are rigged ahead of time. One limiting factor is the time required to spool the mooring wire onto the winch if this has not already been done. 
With the above completed, the bottom-detecting device is armed (i.e., the glass ball is inserted and the safety pin is installed to secure the piston against tripping on deck) and its 150 -foot pilot pennant (usually $3 / 16^{-i n c h}$ wire rope) is faked out near the work platform. One end of this pennant is attached to the detecting device and the other end is attached to the bottom eye on the anchor. A special swivel is then attached to the top pad eye of the anchor, and to this is attached a 300 -foot steel rope pennant ( $3 / 16$-inch, $3 \times 19$ improved plow steel). This latter pennant is then faked out and the bitter end is shackled to the special wire clamp which has been attached to the terminal end of the mooring wire. $\mathrm{A} 5 / 8$-inch manila tag line leading through a snateh block on the work davit is then tied to the top pad eye on the anchor.

The instrument skiff is put on the launching skids (a cradle made of wood four-by-fours flush with the gunwale just aft of the work platform). The 300 -foot nylon mooring pennant marked every 50 feet is snapped into the ring of the 20 foot skiff painter, and then faked down alongside the launching skids. The subsurface float, already pressurized, is next moved into the work area and its 10 -foot wire-rope pennant is shackled to the lower side while the 300 -foot nylon pennant is shackled to the top eye.

The metering device for the mooring wire is set, and the echo-sounder loudspeaker located at the work platform is tested. The ship is then ready to moor a skiff.

\section{MOORING PROCEDURE}

On approach to the station, the bridge notifies the working crew to stand by fifteen minutes before arrival. At this time all connections in the system are checked to make certain that shackles are moused, that shackle pins have micarta sleeves and washers, and that all fittings have been painted with plumbers' black mastic. The instruments in the skiff are then activated and the skiff light is connected with the batteries.

As the ship approaches the station's planned position, speed is reduced and the ship is headed up into the wind and sea. When the ship is relatively motionless on station (as checked by sea-marker dye or other means), a sounding is taken and the echo sounder is then put on "listen" so that any pretripping of the bottomdetecting device can be picked up. Depending on the ship, all mooring work is carried out over the port side aft, for example, and caution is exercised so that the ship does not fall off to port. If this happens, the wire tends to work under the ship. Almost the only recourse in the event this happens is to cut the mooring wire, if it has not parted already, and to start over. It is virtually impossible with any amount of wire out, once the ship has ridden over it, to maneuver so as to clear it. The bridge notifies the fantail when on exact geographic position and ready to begin laying the mooring.

The first thing over the side is the bottom-detecting device. The safety pin is removed and the device (weighing about 70 pounds) is lowered by hand on its own 150 -foot wire rope. While the bottom-detecting device is being lowered, the anchor (about 700 pounds) is hoisted outboard by chain falls and the weight is taken on the $5 / 8$-inch manila tag line. When the 150 -foot wire rope is out, it hangs from the 
bottom eye of the anchor. Next, the $5 / 8$-inch manila tag line, which carries all the weight, is eased out, and the anchor's 300 -foot wire-rope pennant is payed out under slight tension to avoid fouling. When the 300 -foot wire-rope pennant is completely payed out, the strain is eased onto the mooring wire from the manila tag line. Once the mooring wire has the strain, the manila tag line is cut and the winch operator starts lowering away under power. After several hundred meters of wire are out, the winch is stopped, the motor is disengaged, and the remainder of the lowering is done using only the brake. The optimum lowering rate is between 150 and 200 meters per minute. The winch operator has to be extremely alert, taking into account the roll of the ship and working with it. Failure to do this may cause a sharp jerk, which might pretrip the bottom-detecting device or even part the wire. Sudden slack in the wire may cause it to jump the sheave, usually at the level wind at the winch. If the wire does not part when it jumps this sheave, there is a very good chance that it will part in the process of getting the wire back into the sheave. It usually takes about 30 minutes to lower the mooring wire on a 2,500-fathom station.

The wire must be very close to vertical when approaching the bottom. If there is a noticeable wire angle, the winch is stopped until the ship can maneuver to eliminate it.

Paying particular attention to the amount of wire out and to the depth, the winch operator begins slowing down about 200 meters off the bottom so that he can stop the winch quickly but smoothly when the implosion of the glass ball is heard on the loud-speaker. If the bottom-detecting device fails to function for any reason, then the winch operator must "braille" for bottom by noting the slackening of the wire when the anchor touches bottom. A dynamometer for this purpose is useful, but a good winch operator can detect the reduced tension immediately. As there is a time lag for the bottom-detector signal to reach the surface, plus the operator's personal reaction time, if the bottom-detecting device hits the bottom accidentally before the winch is slowed down, it is assumed that approximately 20 meters of the pilot line between the anchor and the bottom detector are lying on the bottom when the lowering stops. Thus, as soon as the winch is stopped, a meter reading of the amount of wire out is taken and then the winch operator hauls in 20 meters. A sounding is taken at this time and recorded. At this point, the bottom-detecting device is on the bottom with the anchor suspended on the mooring wire 150 feet above it.

The special wire clamp is now secured to the standing part of the mooring wire, then the 10-foot wire-rope pennant from the subsurface float is shackled into the special clamp. The shackle is moused and the whole assembly coated with plumbers' black mastic. The wire pennant and the nylon pennant leading to the skiff are all rigged outboard and clear. The weight is still on the mooring wire.

On signal from the work platform, the winch operator lowers away slowly under power and the subsurface float is eased into the water by tag line. As soon as the float becomes water-borne, the load on the winch is greatly reduced. The winch operator continues to pay out until the anchor is on bottom, at which time it may be determined if the subsurface float is down to the proper depth. This may be roughly gauged by the 50 -foot markers on the nylon pennant. In the event that 
the float is not at the proper depth, it may be retrieved by hauling in with the winch and changing the position of the special wire clamp along the wire. When the depth of the float is judged to be right, the mooring wire is cut outboard of the sheave.

The bridge, notified that the float is down, now executes a slow left turn to keep clear as the remainder of the nylon pennant is payed out. The safety lines are released from the instrument skiff, and several hands stand by to launch the skiff. As the last of the slack goes out of the nylon pennant, the skiff is pushed overboard on a port roll. If the skiff on the launching pads is not more than 8 or 10 feet above the water, it slips into the water quite easily and without undue shock to its instrumentation.

The ship now stands clear of the station. Usually in fifteen or twenty minutes the station becomes oriented to the wind and the sea, at which time the ship may make a careful approach from downwind to obtain a last check on the station's exact geographical position.

\section{SERVICING INSTRUMENT STATIONS}

When several stations are to be serviced on a routine basis, the vessel will normally carry at least one complete instrument station ready for launching. On arrival at a station to be serviced, the ship approaches the mooring upwind, keeping the moored skiff close aboard off the port side. As the skiff comes alongside, a grapnel is thrown over the mooring pennant and the pennant is hauled on board. The ship continues to ease up on the starboard side of the mooring. The moored skiff is disconnected and its painter snapped onto a recovery line, which has been led forward from the skiff ramp and outboard of everything. The skiff is then permitted to drift astern. The mooring pennant, which has been hauled on board, is now passed aft, outboard of all lines, and connected by the snap ring to the painter of the ready instrument skiff. The ship continues to ease past the mooring and the mooring pennant is payed back out. The ready skiff on launching rollers or rack at a convenient location on the port quarter, where it can be launched easily, is cleared for launching with men standing by. When all the slack in the mooring pennant is payed out, the skiff is launched.

During this time another group has lowered the skiff-retrieving ramp and the skiff station being replaced is hauled on board, and the ramp is secured. Once the skiff is on board, the records are recovered and the skiff is reinstrumented and readied for exchange at the next station. Once the system is worked out it takes about fifteen minutes on station to make the exchange of instrument skiffs, and the reinstrumentation is accomplished while the ship is en route to the next station.

Weather affects the facility with which stations can be serviced and exchanged. Stations have been exchanged, however, in winds up to 35 knots without much difficulty, and experience indicates that the operation could be performed under considerably worse conditions.

\section{Anchoring Problems}

In connection with anchoring problems in general and the anchoring of moored oceanographic stations in particular, questions repeatedly arise in reference to 
(a) the holding qualities of various types of bottom deposits, and $(b)$ the holding power of various types of anchors and anchoring systems. It would be very useful to have a yardstick with which the anchor-holding qualities of bottom deposits could be measured, or to have some easily measured characteristic to which they could be related.

At least one attempted approach to this problem has been published (Continental Copper and Steel Industries, 1956), and no doubt there are others. Because this report indicates the kind of useful information that can be obtained, the following extracts from it are included here (bearing in mind that it describes conditions in a particular area):

The ocean bottom conditions in this area are likely to be stratified layers of inorganic clays, globigerina ooze and sands. The sedimentary layers grade both laterally and vertically into different kinds of sediments. Inorganic clay is the predominant sediment.

Bearing strength of this deep-sea material can be inferred: it probably behaves like sub-aerial sediments of the same type and characteristics. A few direct observations are pertinent. Glacial, ice-rafted boulders weighing seventy-five pounds have been dredged from the surface of the deep sea clays. We infer from this that roeks of density 2.50 have not sunk deeply into the bottom mud since the glacial age. A few scattered soil tests have been made on disturbed samples taken by coring devices. One sample was subjected to consolidation tests and the natural water content, and the liquid plastic limit has been established.

From these tests the cohesion ean be estimated to be, between zero and five feet below ocean bottom, two hundred pounds per square foot. From then on, the cohesion increases to approximately three hundred pounds per square foot at a depth of eleven feet and this increase continues.

Concerning the holding power of anchors, Riesenberg (1936) describes pulling tests on two types of stockless anchors in three types of bottom (soft mud, hard sand and gravel, and hard clay). Anchor A weighed 3,145 pounds, and anchor B weighed 2,375 pounds. The results of the tests (as read on a 100-ton gauge) are shown in table 3 . The scope of chain in the above tests varied between approximately 5 and 9 , and the pull-out tensions varied from zero to approximately five times the weight of the anchors. By comparison, as shown in table 4, the holding power of at least one common type of anchor is claimed (by a supplier) to be "up to sixty times the weight of the anchor."

Common types of anchors in general use are designed to be most effective when the pull is parallel or nearly parallel to the bottom. The weight of the attached

TABLE 3

Holding Power of BotTom

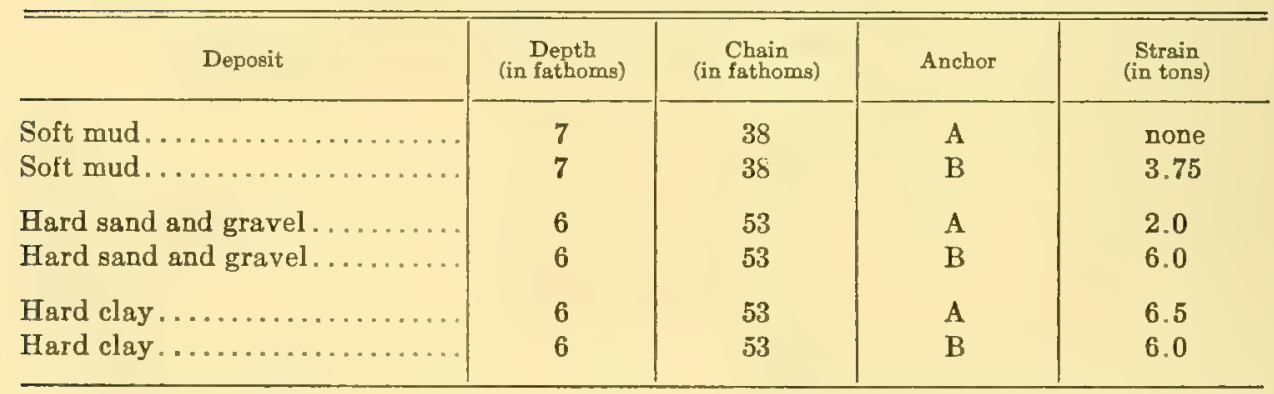


cable and the scope are normally depended upon to minimize the vertical component of tension at the anchor. As the depth of water increases and the practical limits of scope decrease, the weight of the anchor assumes greater importance. In taut mooring, where the pull is vertical or nearly so, the weight of the anchor usually predominates over other holding characteristics.

TABLE 4

Comparison of ANCHORS

\begin{tabular}{|c|c|c|c|c|}
\hline \multirow{2}{*}{ Northill folding anchor number } & \multirow{2}{*}{$\begin{array}{l}\text { Approximate } \\
\text { holding power } \\
\text { (in pounds) }\end{array}$} & \multicolumn{3}{|c|}{$\begin{array}{c}\text { Comparative anchor weight for same holding power } \\
\text { (in pounds) }\end{array}$} \\
\hline & & Northill & Kedge & Stockless \\
\hline $6 \ldots \ldots \ldots \ldots \ldots$ & 240 & 6 & 35 & 60 \\
\hline $12 \ldots \ldots \ldots \ldots \ldots \ldots \ldots$ & 720 & 12 & 100 & 180 \\
\hline $20 \ldots \ldots \ldots \ldots \ldots \ldots$ & 1200 & 20 & 170 & 300 \\
\hline $30 \ldots \ldots \ldots \ldots \ldots \ldots \ldots \ldots \ldots \ldots \ldots \ldots$ & 1800 & 30 & 260 & 450 \\
\hline $50 \ldots \ldots \ldots$ & 2500 & 50 & 360 & 825 \\
\hline 80 & 3600 & 80 & 500 & 900 \\
\hline 100. & 4500 & 100 & 570 & 1000 \\
\hline
\end{tabular}

Holding Power of Northill Utmity ANchor

\begin{tabular}{|c|c|c|}
\hline Anchor number & $\begin{array}{l}\text { Anchor weight } \\
\text { (in pounds) }\end{array}$ & $\begin{array}{l}\text { Approximate } \\
\text { holding power } \\
\text { (in pounds) }\end{array}$ \\
\hline $6 R \ldots \ldots \ldots \ldots \ldots$ & 13 & 450 \\
\hline $12 R \ldots \ldots \ldots \ldots \ldots \ldots \ldots$ & 25 & 900 \\
\hline$\ldots \ldots \ldots \ldots \ldots \ldots$ & 47 & 1575 \\
\hline $30 R \ldots \ldots \ldots \ldots \ldots \ldots \ldots$ & 70 & 2100 \\
\hline $50 R \ldots \ldots \ldots \ldots \ldots \ldots \ldots$ & 150 & 2625 \\
\hline
\end{tabular}

Various methods have been employed to increase the holding power and to minimize the vertical components of tension at the anchor. These have included the use of heavier components of cable adjacent to the anchor and of special weights or "clumps" ahead of the anchor. In some instances the weight of the clump may be several (three or more) times the weight of the anchor itself.

In taut moorings, the situation is essentially reversed although the components used may be very similar; that is, the weight or clump itself becomes the anchor and a small drag anchor is provided to back it up.

If it is necessary to place the anchor on a steeply inclined bottom, special provisions may be necessary to prevent it from dragging. Various sophisticated designs of anchors have been proposed for use in special situations. Most suggestions have been directed toward reducing the weight while increasing the holding power. Some have included various means of "burying" the anchor by driving, screwing, or otherwise forcing something into the bottom or by using a jet to make a hole, which then closes about the anchor. In order to reduce the lowering stresses on the mooring cable in deep water, some means of "floating" the anchor down 
may be desirable.* An embedment-type explosively propelled anchor has been designed by the Cleveland Pneumatic Company, Advanced Systems Division, El Segundo, California, and is in use for depths such as those with which we are dealing.

It should be kept in mind that in installing the anchor, the only exact measure of depth is made with the wire. If the anchor is very light or has high drag, this measurement will be inaccurate. This inaccuracy also obtains with an anchor in free or nearly free fall.

\section{Retrievability of Submerged Float}

Generally, it will not be worth while, because of the relatively low cost of the anchor and the mooring wire as compared with the value of ship's time, to try to recover a complete mooring. Also, depending on the length of time the mooring has been in and the stresses that have been applied to the wire during installation, use, and recovery, it may not be wise to use it again. Above all, the potential hazard to personnel involved in recovery has made us hesitate to recommend recovery of the moorings as a general practice, although we have recovered the upper sections, including the submerged float, for purposes of inspection.

One of the hazardous points involved in recovery is that the wire may part beneath the submerged float, permitting it to "free balloon" to the surface with enough force to cause damage to the ship's propellor, rudder, or hull. If a 3-footdiameter steel sphere, of a type used on deep moorings, is released while submerged, it will reach a terminal upward velocity of 8 feet per second in 3 seconds. On reaching the surface with this velocity it will partly or wholly emerge. If inflated rubber drums are used for the submerged float, the hazard is diminished.

\section{Corrections to Echo-Sounder Readings for Sound Velocity}

The velocity of sound in water varies as a function of depth, temperature, and salinity. Most sonic depth-finding instmments are adjusted for a constant sounding velocity, usually 800 to 820 fathoms (1,460 to 1,500 meters) per second. In certain cases it is desirable to correct the readings to true depths. This can be done if the distributions of temperature and salinity are known. For different areas of the oceans and for different depths, the British Admiralty Tables (Mathews, 1927) contain mean sounding velocities, that is, mean velocities from the surface to the stated depth. In general, these first decrease somewhat with depth, because the effect of decreasing temperature predominates, but at greater depths they increase again as the pressure effect becomes dominant. Figure 11 indicates the magnitude of the correction to the indicated echo soundings for one area of the ocean.

When an accurate depth determination is essential, a deep hydrographic cast is in order to measure temperature and salinity at intervals from the surface to the bottom.

* This places extreme requirements on the handling of the winch, because the wire is capable of sinking faster than the "floated" anchor. 


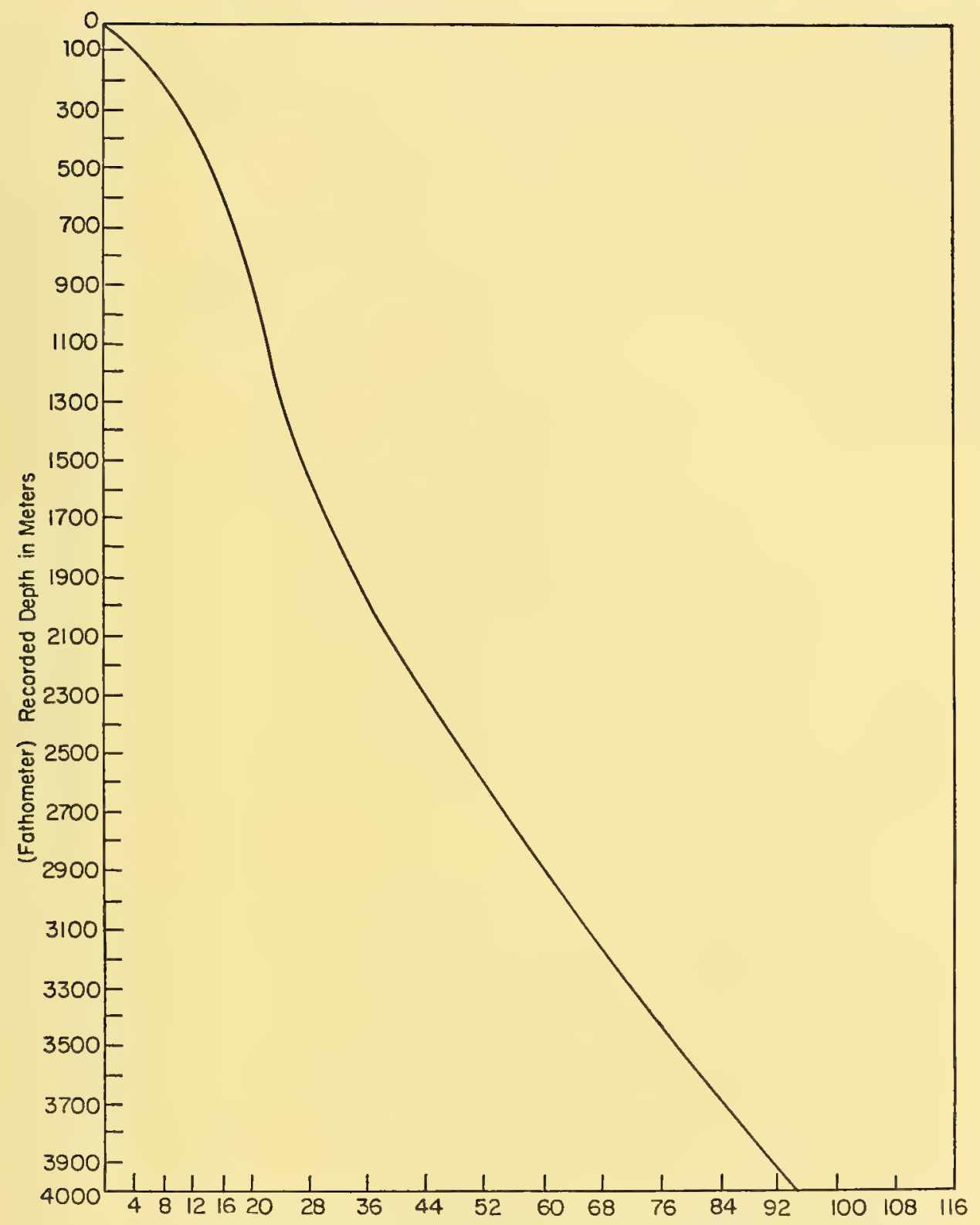

Fig. 11. Correction (in meters) to be added to recorded depth. This is an example only, using data typical of an area in the Marshall Islands.

\section{TaUt-NyLon Mooring}

The taut-wire subsurface float mooring, heretofore described, probably will prove to be the optimum type when no surface float or only surface measurements are required. The optimum type of mooring, for the case where deep subsurface parameters must be received at the surface, has not yet been designed. It is here 
the really difficult problems occur. A surface pennant must be highly elastic if it is to be vertical, or, if nonelastic, it must be allowed to float for some distance on the surface, where it is liable to fouling by ships. Moorings with slack surface pennants are easy prey to theft or to retrieval by helpful itinerants, and the installation of transducers along a slack surface pennant is not satisfactory, because their depth cannot be controlled.

In an attempt to solve some of these problems, a somewhat different type of mooring is now under development, using a $3 / 8$-inch taut nylon mooring line without a submerged float. In order to maintain the station-keeping ability of the taut-wire mooring, the new nylon mooring is designed to be under a tension of 300 to 400 pounds at all times. To achieve the desired tension the mooring is installed so that the line is stretched about 15 per cent. This requires prior knowledge of the depth where the mooring is to be installed.

In order to support a vertical mooring line with 300 to 400 pounds tension a new catamaran-type instrument float (fig. 12) was designed with the mooring line attached nearly amidships. The catamaran has other advantages over conventional boat-shaped floats. It permits the mooring line to be fastened below the deck in such a manner that theft or retrieval by unauthorized persons is difficult. It affords a large, flat, stable deck, which facilitates servicing or repair, and it is not very attractive to potential pirates.

Use of a taut nylon mooring line assumes that the nylon will have sufficient elasticity to withstand the wave-induced excursions of the surface float. Our experience indicates that the nylon retains its elasticity for periods of at least one year, and exhibits no measurable creep or shrinkage after installation. We have made two successful installations of this type of mooring in 300-fathom depths, and they are still performing satisfactorily.

\section{Basic Computations for Drag Forces on the Mooring}

Depending on the stage of planning, we will require either (1) first approximations for determining feasibility and as a basis for further consideration, or (2) precise information of the type required for the placing of orders for materials. For most purposes the simplified formulas given in the section on system design will, when used with discretion, provide the degree of accuracy required for estimating the forces on a mooring. These formulas, however, should be applied with some caution, as the following discussion indicates. Additional background may be found in Rouse (1946).

The force exerted by a fluid flowing past a submerged object at a steady rate may be expressed as

$$
\mathrm{F}=\mathrm{C}_{\mathrm{D}}(\mathrm{W} / 2 \mathrm{~g}) \mathrm{AU^{2 }}
$$

where $\mathrm{F}$ is the fluid force, usually referred to as the total drag force (a combination of skin drag and form (rag); $C_{D}$ is a dimensionless drag coefficient; $W$ is the specific weight of the fluid (weight per unit volume); $g$ is the acceleration of gravity; $\mathbf{A}$ is the projected area of the object that intercepts the flow; and $U$ is the undisturbed speed of the fluid. Strictly speaking, this equation applies only when the object is small compared with the dimensions of the fluid, far from the boundaries, and only when the undisturbed velocity of the fluid is uniform as well 

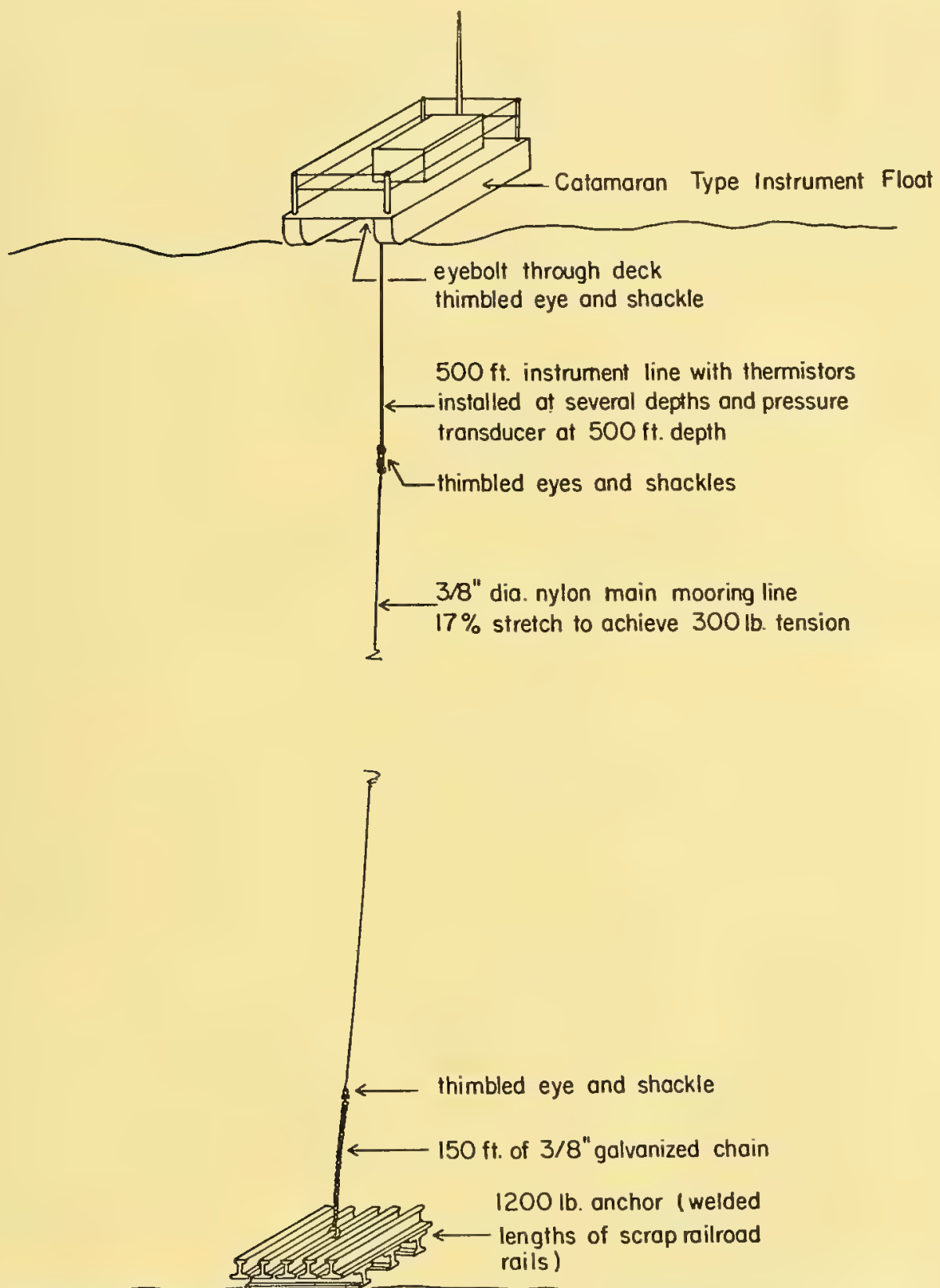

Fig. 12. Taut-nylon deep-water mooring system, by Scripps Institution of Oceanography.

as steady. Practically speaking, this means that the variation of the undisturbed velocity should be small over a distance equaling the largest dimension of the object.

To conform with standard engineering practice, the English system of units 
is adopted in the presentation here. Thus, with $\mathrm{W}$ in pounds per cubic feet, $\mathrm{g}$ in feet per second squared (32.2), A in square feet, and $U$ in feet per second, the value of $\mathrm{F}$ from equation (19) will be in pounds. For sea water, $\mathrm{W}$ is about 64 pounds per cubic foot, so that $\mathrm{W} / 2 \mathrm{~g}$ is just about unity, thus simplifying the expression for the drag force as follows:

$$
\mathrm{F}=\mathrm{C}_{\mathrm{D}} \mathrm{AU^{2 }}
$$

The drag coefficient $\mathrm{C}_{\mathrm{D}}$ depends upon the shape and the roughness of the object and on the Reynolds number Re, associated with the flow. The Reynolds number is defined by

$$
\mathrm{Re}=\mathrm{UD} / \nu
$$

where $\mathrm{D}$ is the effective diameter of the object and $v$ is the kinematic viscosity of the fluid. For water at $70^{\circ} \mathrm{F}, v$ is about $10^{-5}$ square feet per second. Consequently, the following expression for Re is valid for problems dealing with flow of water around obstacles:

$$
\operatorname{Re}=10^{5} \mathrm{UD}
$$

If the submerged object is a circular cylinder or a sphere, then the effective diameter is the actual diameter. The values of drag coefficients for smooth circular cylinders of large length-to-diameter ratio, with the axis perpendieular to the flow, are presented in table 5, prepared from data in Rouse (1946). The ranges of Reynolds numbers represented are those encountered in most engineering

\begin{tabular}{|c|c|}
\hline Reynolde number (Re) & Drag coefficient (CD) \\
\hline $10^{3}$ to $10^{4} \ldots$ & 1.0 \\
\hline $10^{4}$ to $2 \times 10^{5}$ & 1.2 \\
\hline Larger than $5 \times 10^{5} \ldots$ & 0.33 \\
\hline
\end{tabular}

TABLE 5

Drag Coefficients

problems. The values have been obtained from laboratory studies under conditions of steady (unaccelerated) flow.

The results of these laboratory experiments indicate that there exists a critical value of Reynolds number above which the regime of disturbed flow around the object is changed abruptly, leading to a decrease of $\mathrm{C}_{D}$. Not much information is available for roughened cylinders; however, the indications are that $(a)$ for lowerthan-critical Re the value of $C_{D}$ is essentially unchanged; $(b)$ for higher-thancritical Re the value of $C_{D}$ is larger than that for a smooth surface; and $(c)$ the value of the critical Re is somewhat redueed. A brief series of tests which we conducted indicate that the drag of twisted wires is somewhat less at higher Reynolds numbers, possibly because of spoiling.

The value of $\mathrm{C}_{\mathrm{D}}$ for a long flat plate of width $\mathrm{D}$ is about 2.0 (or about 6 times the value of $\mathrm{C}_{\mathrm{D}}$ for a cylinder at high Reynolds numbers), and apparently has no critical value of $\mathrm{Re}$ in the range $3 \times 10^{3}$ to $10^{6}$.

\section{Steps in the Graphic Solution of a Deep-Mooring Configuration}

Step 1. Measure or assume velocity distribution

Step 2. Calculate $\mathrm{V}^{2}$ 
Step 3. Calculate drag frontal area of wire

Step 4. Calculate drag of various components

Step 5. Calculate weight in water $\mathrm{F}_{\mathrm{V}}$ of various components

Step 6. Sum weight, $\mathrm{F}_{\mathrm{V}}$ and drag $\mathrm{F}_{\mathrm{H}}$ (individually)

Step 7. Calculate wire angle $=\operatorname{arc} \tan \mathrm{\Sigma F}_{\mathrm{H}} / \mathbf{\Sigma} \mathrm{F}_{\mathrm{V}}$

The wire shape may now be derived graphically by constructing successive force-vector diagrams starting at the anchor and proceeding upward as shown in table 6 and figure 13 . Note that figure 13 shows the graphic steps of only the lower three segments into which the mooring has been divided. Foree diagrams and configuration are simultaneously constructed.

\section{TABLE 6}

\section{Sample Calculation of Forces}

(Sample calculations for a mooring using 2,500 fathoms of .120-inch piano wire which weighs 500 pounds and has a breaking strength of 3,190 pounds. As the anchor for this mooring must weigh a minimum of 536 pounds or a maximum of 1,414 pounds, an anchor weighing from 700 to 900 pounds would be a reasonable choice.)

\begin{tabular}{|c|c|c|c|c|c|c|c|c|}
\hline $\begin{array}{c}\text { Depth } \\
\text { (fathoms) }\end{array}$ & $\underset{\text { (knots) }}{\mathrm{V}}$ & $\underset{(f t / s e c)}{V}$ & $\begin{array}{c}V^{2} \\
\left(\mathrm{ft}^{2} / \mathrm{sec}^{2}\right)\end{array}$ & $\begin{array}{l}\text { Area } \\
\left(\mathrm{ft}^{2}\right)\end{array}$ & $\underset{\left(\text { lbs. }_{\text {o }}\right)}{\mathrm{FH}_{\mathbf{H}}}$ & $\underset{(\text { lbs.) }}{\sum F_{\text {H }}}$ & $\begin{array}{c}\mathrm{Fv} \\
(\mathrm{lbs} .)\end{array}$ & $\underset{(\mathrm{lbs} .)}{\Sigma \mathrm{Fv}}$ \\
\hline Skiff. & $\ldots$ & $\ldots$ & $\ldots$ & $\ldots$ & 90.0 & $\ldots$ & $\ldots$ & $\ldots$ \\
\hline Buoy..... & $\ldots$ & $\ldots$ & $\ldots$ & . & 10.0 & 100.0 & -780 & -780 \\
\hline $100-200 \ldots \ldots \ldots$ & 1.00 & 1.69 & 2.86 & 6 & 18.9 & 118.9 & +40 & -740 \\
\hline $200-300 \ldots$ & 0.750 & 1.27 & 1.62 & 6 & 10.7 & 129.6 & 20 & -720 \\
\hline $300-500 \ldots$ & 0.486 & 0.818 & 0.669 & 12 & 8.9 & 138.5 & 40 & -680 \\
\hline $500-1000 \ldots$ & 0.439 & 0.742 & 0.550 & 30 & 18.2 & 156.7 & 100 & -580 \\
\hline $1000-1500 \ldots$ & 0.370 & 0.626 & 0.392 & 30 & 13.0 & 169.7 & 100 & -480 \\
\hline $1500-2000, \ldots$ & 0.302 & 0.512 & 0.262 & 30 & 8.6 & 178.3 & 100 & -380 \\
\hline \multirow{2}{*}{$\begin{array}{l}2000-2500 \\
\quad(\text { bottom) ....... }\end{array}$} & & & & & & & & \\
\hline & 0.234 & 0.397 & 0.158 & 30 & 5.0 & 183.3 & 100 & -280 \\
\hline
\end{tabular}

\section{Calculation of Restoring Forces on a Surface Float}

Imagine a pennant having $\mathrm{n}$ floats equally spaced along its length. Let the slope of the pennant at the submerged float of the taut mooring be $\theta_{1}$, and the slope at the skiff be zero. Then as an approximation we may consider that at each line float the slope of the pennant changes by the same amount $\Delta \theta$, and that it is perfectly straight between floats. Then

$$
\Delta \theta=(1 / n) \theta
$$

and the slope above the $\mathrm{mth}$ float (fig. 14) is expressed by

$$
\theta_{\mathrm{m}}=\theta_{\mathrm{m}-1}-\Delta \theta
$$

If $F_{B}$ is the buoyancy of a float, then the force it exerts in a direction at equal angles to the two pennant segments above and below it is expressed by

$$
\mathrm{F}_{\mathrm{b}}=\cos \left(\theta_{\mathrm{m}-1}-1 / 2 \Delta \theta\right) \mathrm{F}_{\mathrm{B}}
$$

Therefore the force in the direction of the pennant segment above the float and in the downward sense is expressed by

$$
\mathrm{F}_{\mathrm{p}}=1 / 2 \mathrm{~F}_{\mathrm{b}} / \sin 1 / 2 \Delta \theta
$$

Although it is clear that the figure assumed for the array is imaginary and never, 
ASSUMEO HORIZONTAL VELOCITY PROFILE Vand $V^{2}$ vs.d
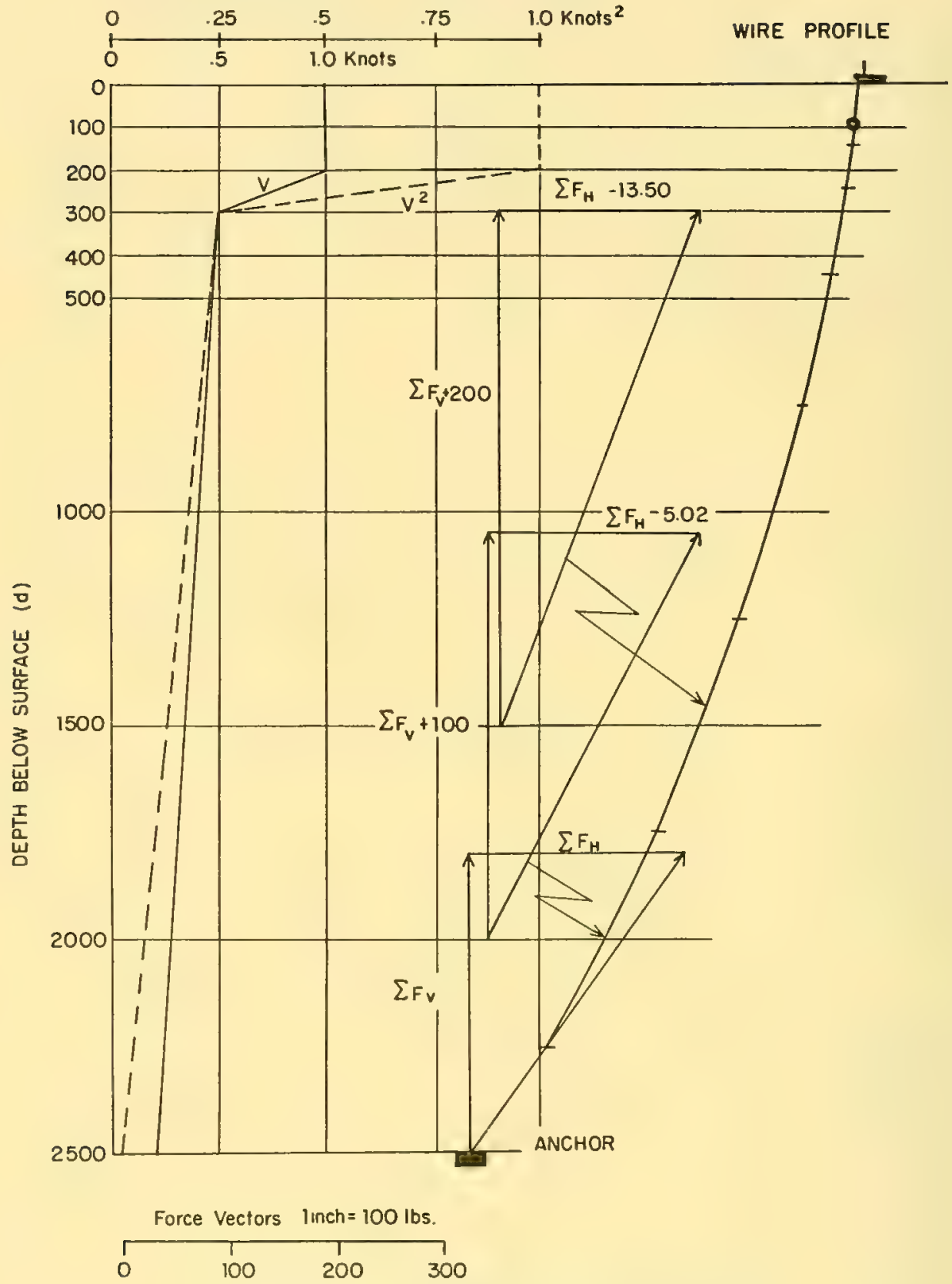

Fig. 13. Graphic solution of deep-mooring configuration.

in fact, occurs, it is sufficient to use as a basis for calculating the magnitude of the effects of a buoyant pennant.

The force parallel to the sea surface is expressed by

$$
\begin{aligned}
\mathrm{F}_{\mathrm{h}} & =\mathrm{F}_{\mathrm{p}} \cos \left[90^{\circ}-\left(\theta_{\mathrm{m}-1}-\Delta \theta\right)\right] \\
& =\mathrm{F}_{\mathrm{p}} \sin \left(\theta_{\mathrm{m}-1}-\Delta \theta\right)
\end{aligned}
$$


For a 300 -foot pennant with scope 2.0 and ten equally spaced floats having a buoyancy of 4.5 pounds each, if the angle at the submerged buoy is 60 degrees, the total force in a horizontal direction is

$$
\begin{aligned}
\mathrm{\Sigma} \mathrm{F}_{\mathrm{h}} & =43.3 \mathrm{\Sigma} \cos \left(\theta_{\mathrm{m}-1}-1 / 2 \Delta \theta\right) \sin \left(\theta_{\mathrm{m}-1}-1 / 2 \Delta \theta\right) \\
& =43.3 \times 3.2=138 \text { pounds }
\end{aligned}
$$

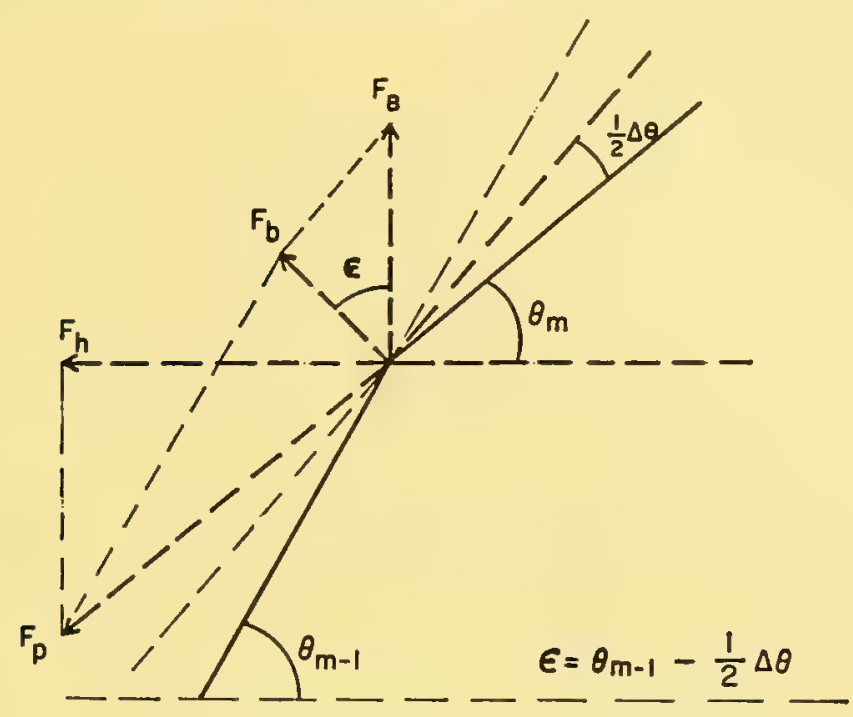

Fig. 14. Restoring forces on a pennant.

The initial horizontal restoring velocity at the skiff may then be calculated, using the following assumed form drag areas.

A half-inch pennant reaching to 150 feet $(1 / 2 \times 1 / 12 \times 150) \ldots 6.3 \mathrm{sq}$. ft.

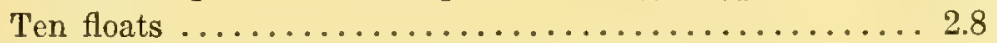

A vertical instrument line with instruments......... 3.0

Equivalent form drag area of skiff $(20 \times 0.01) \ldots \ldots \ldots . .2$

12.3 sq. ft.

$$
\mathrm{v}_{0}=\sqrt{(2 \times 138) /(1.2 \times 12.3 \times 2)}=3 \mathrm{ft} \text {. per second }
$$

which exceeds the requirement of 2.5 feet per second set by a hypothetical storm wave 25 feet high.

This result is not very sensitive to changes in the figure of the pennant except under two conditions. The first is the improbable condition that combers might occur when there is little wind or surface current. The second is that the pennant is stretehed so that $\theta_{\mathrm{m}}$ at every float is less than $30^{\circ}$. In this instance, however, the elastic stretching of the pennant rapidly increases the restoring force, as already noted. When the skiff is being driven by the cascading comber, its bow is deep in the water and $C_{D} \approx 1.0$. When it surmounts or reaches the terminus of the comber, it floats higher, especially at the bow, and $C_{D} \approx 0.01$. There is thus a large effective force available to stretch the pennant, of which a small proportion is sufficient, when added to the buoyancy of the floats, to make up the required restoring force. 


\section{LITERATURE CITED}

Bascom, W. N.

1953. A deep-sea instrument station. Scripps Inst. of Oeeanogr. Tech. Rep., SIO Ref. 53-38.

ConTINental CopPer AND SteEL INDUSTRIES, INC.

1956. Feasibility report on continental defense station. Mass. Inst. Tech., Lineoln Labs.

IsAACS, J. D., R. P. HUFFER, and L. KIDD

1957. Science, $125: 341$.

MARES, L. S.

1958. Mechanical engineers' handbook. 6th ed. New York, McGraw-Hill.

Mathews, D.J.

1927. Tables of the velocity of sound in pure water and sea water for use in echo-sounding and echo-ranging. British Admiralty, Hydrographic Dept., HD no. 282.

RIESENBERG, $\mathrm{F}$.

1936. Standard seamanship for the merchant service. $2 d$ ed. New York, Van Nostrand.

ROUSE, HUNTER

1946. Elementary mechanies of fluids. New York, John Wiley.

SvERDRUP, H. U., M. W. Johnson, and R. H. FleMing

1942. The oceans. New York, Prentice-Hall.

SYSOYEV, N. N.

1957. Development of the techniques and methods of work at anchor stations for the observation of currents in the oceans. Trudy Inst. Oceanol. Acad. Sci., USSR, vol. 25, pp. 7-24.

(In Russian. English translation available at SLA Translation Center, John Crerar Library, Chicago.)

\section{U.S. NAVY}

1955-1959. Marine Climatic Atlas of the World. NAVAER 50-1c, 5 vols.

U.S. NAVY HYDROGRAPHIC OFFICE

1944-1947. Atlas of Surface Current. HO 566, 568, 569, 570, 571.

1947. Wind wares at sea, breakers and surf. HO 602.

WIEGEL, R. L.

1954. Gravity waves, Tables of Functions. Berkeley Council on Wave Research. 


